dos Santos, G.B., Gardner, L. (2019) Testing and numerical analysis of stainless steel I-sections under concentrated end-one-flange loading. Journal of Constructional Steel Research, 157, 271281.

\title{
Testing and numerical analysis of stainless steel I-sections under concentrated end-one-flange loading
}

\author{
G. B. dos Santos ${ }^{\mathrm{a}, *}$, L. Gardner ${ }^{\mathrm{a}}$ \\ ${ }^{a}$ Department of Civil and Environmental Engineering, South Kensington Campus, Imperial College London, London \\ SW7 2AZ, UK
}

\begin{abstract}
A comprehensive investigation into the structural behaviour of austenitic stainless steel welded Isection beams under concentrated transverse end-one-flange loading is reported herein. Ten physical experiments are first described. The experimental results are then presented in terms of the full loadweb shortening responses, ultimate loads, out-of-plane deformation fields and failure modes. An extensive finite element modelling study accounting for geometric, material and contact non-linearities was also performed. After successful model validation against the test results, a parametric investigation was conducted considering a range of bearing lengths, different distances of the bearing load to the member end and web slenderness values. The combined experimental and numerical data set was used to assess current European and North American design provisions for the resistance of stainless steel welded I-sections to concentrated end-one-flange loading. The results show that the current design formulae generally lead to safe-sided but rather scattered and conservative capacity predictions with considerable scope for the development of improved design formulae.
\end{abstract}

Keywords: Austenitic stainless steel; concentrated transverse load; experiments; finite element modelling; end-one-flange (EOF); testing.

\section{INTRODUCTION}

Structural steel elements are often subjected to concentrated transverse loading such as in beam-tocolumn connections [1] or at permanent or temporary beam loading points and supports [2]. Members 
under these loading conditions are subjected to non-uniform stress distributions, complex edge restraint conditions and local yielding beneath the load [3]. Taken together, these features render the development of analytical formulations able to predict accurately the ultimate resistance of members under concentrated loading challenging. In fact, even the determination of the key reference loads i.e. the elastic buckling load and plastic collapse load is non-trivial - analytical models for their estimation $[4,5]$ are still complex while the use of numerical techniques $[6,7]$ is often necessary, particularly for less standard cases.

Experimental investigations into the ultimate bearing resistance of cold-formed steel members under concentrated transverse loading date back to 1946, when the first tests on carbon steel members were reported by Winter and Pian [8]. Since then, tests have been performed on cold-formed carbon steel members with different cross-section shapes, including I-sections, C-sections, Z-sections, hat-sections, deck sections, and hollow sections [9-14], on members with and without flange restraints [15-17], on those with web openings [18] and on cold-formed stainless steel members [19-26]. Numerical studies on cold-formed stainless steel [23, 27-29], aluminium [30] and carbon steel members [31] have also been performed. Tests on cold-formed members under concentrated transverse loading are often referred to web crippling tests due to the failure mode exhibited during the experiments. A substantial number of tests has also been performed on hot-rolled and welded carbon steel I-section members subjected to concentrated transverse loading [32-36]. More recently, tests and numerical analysis of stainless steel I-section members under internal one-flange (IOF) loading and internal two-flange (ITF) loading have been performed by the authors [37]; however, still exists very few test results [38] on stainless steel I-section members under end-one-flange (EOF) loading.

The focus of the study is on the structural performance of stainless steel members under end-one-flange (EOF) loading. The load is applied through one flange adjacent to an unstiffened end. Note that for cold-formed sections, the North American specification for the design of cold-formed steel members AISI S100-12 [39] requires the clear distance between the bearing edges to be greater than 1.5 times the section height for EOF loading. The specimens tested herein do not satisfy this requirement, but 
the presence of the stiffener at the loading point ensures that failure is nonetheless due to one-flange loading only, and this is clearly visible in the obtained failure modes. This loading condition is referred to Type (c) loading in EN 1993-1-5 [40]. Ten physical laboratory tests were carried out to investigate the influence of the bearing length, the distance between the end of the bearing length and the end of the member and the distance between the web stiffener and the bearing plate on the ultimate resistance of stainless steel beams under EOF loading; the test procedure and results are reported in Section 2. Following this, numerical models, which were validated using the results from the experiments and then employed to extend the database of results to cover a broad range of practical cases through parametric studies, are presented in Section 3. Finally, the experimental and numerical data are employed in Section 4 to assess the accuracy of existing provisions $[40,41]$ for the design of stainless steel members under end-one-flange loading.

\section{EXPERIMENTAL INVESTIGATION}

Ten end-one-flange loading (EOF) tests were conducted to assess the web bearing strengths of stainless steel I-section members. The specimens were fabricated from hot-rolled Grade EN 1.4307 austenitic stainless steel plates by means of laser-welding in accordance with EN ISO 13919-1 [42]; the quality level was Class B (stringent). Two cross-section sizes were examined: I $140 \times 140 \times 10 \times 12$ and I $160 \times 82 \times 10 \times 10$. The key varied parameters in the EOF loading tests were the bearing length $s_{\mathrm{s}}$, the distance between the web stiffener and the critical support $b$ and the distance between the end of the bearing length and the end of the member $c$; these parameters are illustrated in the experimental setup shown in Fig. 1. The adopted test specimen labelling system identifies the loading type (EOF), the nominal cross-section height $h(140 \mathrm{~mm}$ or $160 \mathrm{~mm})$, the nominal distance between the web stiffener and the critical support $b$ (ranging from $170 \mathrm{~mm}$ to $210 \mathrm{~mm}$ ), the bearing length $s_{\mathrm{s}}(15 \mathrm{~mm}$ or $30 \mathrm{~mm}$ ) and the distance from the critical support to the member end $c$ (ranging from 0 to $20 \mathrm{~mm}$ ); for example, EOF-h140-b180-ss15-c10 indicates a member tested under EOF loading with a nominal cross-section height of $140 \mathrm{~mm}$, a nominal distance between the web stiffener and the critical support of $180 \mathrm{~mm}$, a bearing length of $15 \mathrm{~mm}$ and a distance between the critical support and the member end of $10 \mathrm{~mm}$. In 
the following subsections, the material coupon tests, geometric imperfection measurements and member tests are reported.

\subsection{MATERIAL TESTING}

A comprehensive characterization of the tensile stress-strain properties of the cross-sections tested herein can be found in Gardner et al. [43]; in this subsection, a brief summary of the testing procedure and results is provided. All the tensile coupon tests were performed according to EN ISO 6892-1 [44], using an Instron $8802250 \mathrm{kN}$ hydraulic testing machine. The coupons were extracted from the longitudinal direction of the members (one from the web and one from the flange). A summary of the measured tensile material properties for each cross-section size is given in Table 1, where the Young's modulus $E$, the $0.2 \%$ proof stress $f_{\mathrm{y}}$, the $1 \%$ proof stress $f_{1.0}$, the ultimate tensile stress $f_{\mathrm{u}}$, the strain at the ultimate stress $\varepsilon_{\mathrm{u}}$ and the strain at the fracture $\varepsilon_{\mathrm{f}}$ measured over the standard gauge length, are provided.

\subsection{GEOMETRIC DIMENSIONS AND IMPERFECTION MEASUREMENTS}

Prior to the member tests, the dimensions and geometric imperfections of the specimens were measured. The initial imperfection measurements were taken using the setup shown in Fig. 2 following a similar procedure to that employed in previous studies [37, 45, 46]. A Linear Variable Displacement Transducer (LVDT) attached to the head of a milling machine was employed to record out-of-plane measurements along the top, mid-height and bottom of the web from the web stiffener to the member end while the specimens were lying on a moving machine base. To eliminate the influence of the weld geometry, the measurements were taken $10 \mathrm{~mm}$ away from the web-to-flange and stiffener-to-web junctions, as shown in Fig. 2(a). The web imperfection amplitude $\omega_{0}$ for each member was taken as the difference between the measured mid-height displacement $\left(u_{\mathrm{mid}}\right)$ and the average of the measured top $\left(u_{\text {top }}\right)$ and bottom $\left(u_{\text {bottom }}\right)$ displacements at the centre of the bearing plate (i.e. $c+s_{\mathrm{s}} / 2$ from the member end), as shown in Fig. 3. The measured geometric imperfections and the measured specimen dimensions are reported in Table 2, where $h$ is the overall cross-section depth, $t_{\mathrm{w}}$ is the web thickness, $b_{\mathrm{f}}$ is the overall flange width, $t_{\mathrm{f}}$ is the flange thickness, $a$ is the distance from the member end to the 
first web stiffener, $s_{\mathrm{s}}$ is the bearing length (equal to the bearing height $s_{\mathrm{h}}$ ), $L$ is the beam span, $b$ is the free distance between the loading plate and the bearing plate, $c$ is the free distance between the bearing plate and the member end, $h_{\mathrm{ep}}, b_{\mathrm{f}, \mathrm{ep}}$ and $t_{\mathrm{ep}}$ are the end plate height, width and thickness respectively, $h_{\mathrm{s}}, b_{\mathrm{s}}$ and $t_{\mathrm{s}}$ are the web stiffeners height, width and thickness respectively, $h_{\mathrm{w}} / t_{\mathrm{w}}$ is the ratio of the web height (where $h_{\mathrm{w}}=h-2 t_{\mathrm{f}}$ ) to the web thickness $t_{\mathrm{w}}$ and $\omega_{0}$ is the measured web imperfection amplitude at the centre of the bearing plate.

\subsection{END-ONE-FLANGE LOADING TESTS}

The end-one-flange (EOF) loading test setup consisted of a three-point bending configuration with the load applied through the loading plate at the top flange of the beam, as shown in Fig. 1. The loading plate length was kept constant at $100 \mathrm{~mm}$ for all tests. The bearing plate was positioned at one end of the member and lightly tack-welded to the bottom flange. Rollers were welded to the top of the loading plate and to the bottom of the bearing plate to allow free in-plane rotation. A carbon steel end plate was welded to the opposite end of the member and supported on a roller. At both ends of the members, the rollers rested on plates that were configured to enable the beam to slide horizontally in response to the applied loading. Grease was used between the supporting plates to minimize any friction.

A load cell was positioned under the bearing plate to measure the reaction force at the critical support. The tests were performed using an Instron $88003500 \mathrm{kN}$ hydraulic testing machine under displacement control at a constant rate of $0.005 \mathrm{~mm} / \mathrm{sec}$. Displacement transducers were positioned on the top (DT1) and bottom (DT2) flanges in line with the centre of the bearing plate. Fig. 4 shows the failed specimens, all of which exhibited out-of-plane deformation of the web and flange bending at the bearing point. The load-web shortening responses at the critical support (i.e. at the bearing point) are provided in Figs. 5 and 6 for the $140 \mathrm{~mm}$ and $160 \mathrm{~mm}$ height specimens respectively. Table 2 shows the key test results, where $F_{\mathrm{u}}$ is the ultimate (peak) web bearing load at the support and $\delta_{\mathrm{u}}$ is the vertical web shortening at the bearing point at ultimate load. The web shortening was determined by taking the difference between the measured displacement at the top flange and at the bottom flange of the 
specimen, allowing for the rotation and longitudinal displacement of the member. These results were corroborated by those obtained from Digital Image Correlation (DIC), as described below.

A Digital Image Correlation (DIC) system was used to record the deformation field of the webs of the tested members. A random speckle pattern was first applied to the web surface of each of the tested specimens. Two high-resolution cameras were used to monitor the web region during the tests as shown in Fig. 7. Images were taken at $3 \mathrm{sec}$ intervals and processed using the software DaVis 8.4.0 [47]. Fig. 8 shows the out-of-plane displacement fields for all tested specimens at the area of interest (i.e. between the web stiffener and the member end) at the ultimate web bearing load, $F_{\mathrm{u}}$. As expected, the maximum out-of-plane displacement consistently arose at the critical member end with no significant out-of-plane displacement along the remainder of the member length.

\section{NUMERICAL MODELLING}

Numerical models were developed using the finite element analysis software Abaqus [48]. Initially, the full load-deformation histories and failure modes obtained from the experiments were utilised to validate the numerical models and assess their sensitivity to various parameters. Then, parametric studies were carried out to cover a wider range of cases.

\subsection{MODELLING ASSUMPTIONS}

The four-noded shell element with reduced integration referred to as S4R in the Abaqus element library [48] was used to model the beam including the web stiffeners and the end plate, while the eight-noded linear solid element with reduced integration referred to as C3D8R in the Abaqus element library [48] was used to model the loading and bearing plates. An element size approximately equal to half of the web thickness of the considered I-sections was adopted for the entire model (i.e. loading and bearing plates, I-section, end plates and web stiffeners), on the basis of a preliminary mesh sensitivity study. The measured engineering stress-strain curves obtained using the original data from the tensile coupon tests [43] performed on material extracted from the stainless steel test specimens, were converted into the form of true stress and log plastic strain according to Eqs. (1) and (2) for input into Abaqus, where 
$\sigma_{\text {true }}$ is the true stress, $\varepsilon_{\ln }{ }^{\mathrm{pl}}$ is the true plastic strain, $E$ is the Young's modulus, and $\sigma_{\text {nom }}$ and $\varepsilon_{\text {nom }}$ are the engineering stress and the engineering strain, respectively. The measured material engineering stress-strain curves and the true stress-strain curves for each of the tested cross-sections are shown in Fig. 9.

$$
\begin{aligned}
& \sigma_{\text {true }}=\sigma_{\text {nom }}\left(1+\varepsilon_{\text {nom }}\right) \\
& \varepsilon_{\text {ln }}^{\mathrm{pl}}=\ln \left(1+\varepsilon_{\text {nom }}\right)-\frac{\sigma_{\text {true }}}{E}
\end{aligned}
$$

Elastic material behaviour was assumed for the end plates and the loading plate with a Young's modulus $E$ of $210000 \mathrm{MPa}$ and a Poisson's ratio $v$ of 0.3 . The bearing plate was simulated as a rigid block by constraining all its degrees of freedom to a reference point where the boundary conditions were applied. The boundary conditions were defined to replicate the test setup. A line, constrained to a reference point, was employed at the top of the loading plate to simulate the application of load through a roller. The transverse (U1) and vertical (U2) displacements were restrained at the non-critical support (i.e. at the left-hand end of Fig. 10).

For the bearing plate (i.e. at the right-hand support in Fig. 10), transverse (U1) and vertical (U2) displacements, as well as rotations about the vertical (UR2) and longitudinal (UR3) axes, were restrained. For the loading plate, transverse (U1) and longitudinal (U3) displacements, as well as rotations about the vertical (UR2) and longitudinal (UR3) axes were restrained. Longitudinal displacement was initially restrained $(\mathrm{U} 3=0)$ at the left-hand support, but the restraint was removed (U3 free) once contact between the loading plate and the top flange of the I-beam, as well as between the bearing plate and the bottom flange of the I-beam, had been established.

Surface-to-surface contact was defined between the loading and bearing plates (master surfaces) and the I-section flanges (slave surfaces) to simulate their interaction. A finite sliding procedure [48] was adopted which allows arbitrary motion of both surfaces. A friction coefficient of 0.4 was used for the tangent contact properties while a "hard" contact relationship was adopted for the normal contact 
properties, which assumes that the contact pressure-overclosure relationship is dictated by the stiffness of each of the parts in contact with each other [48].

Residual stresses develop during the fabrication of welded I-sections due to the thermal gradients that arise during the cooling phrase. However, a preliminary study into their influence on the structural response of the modelled I-sections under concentrated loading revealed very low sensitivity; a similar finding was reported for the cross-section resistance of welded I-sections in bending [49]. Hence residual stresses were not incorporated into the numerical models developed herein. Initial geometric imperfections were accounted for by adopting an imperfection pattern corresponding to the first buckling mode shape obtained from a linear eigenvalue buckling analysis, scaled to the measured amplitudes $\omega_{0}$ reported in Section 2.2 at the location shown in Fig. 3. A geometrically and materially non-linear analysis with imperfections (GMNIA) was then carried out using the general static solver [48] with displacement control in order to obtain the full load-deformation responses of the specimens.

\subsection{VALIDATION}

The accuracy of the finite element models was evaluated by comparing the numerical ultimate (peak) load predictions, web shortening values at ultimate load, full load-web shortening responses and failure modes with those observed in the experiments. The numerical and experimental failure modes and the numerical and experimental load-web shortening responses were found to be in close agreement, as shown for the typical case of specimen EOF-h140-b180-ss30-c0 in Figs. 11 and 12, respectively. The ratios of the ultimate load and corresponding web shortening values between the numerical models and the experiments $\left(F_{\mathrm{u}, \mathrm{FE}} / F_{\mathrm{u}, \text { Test }}\right.$ and $\delta_{\mathrm{u}, \mathrm{FE}} / \delta_{\mathrm{u}, \text { Test }}$, respectively $)$ are shown in Table 3 , considering imperfection amplitudes equal to (i) the measured values obtained as described in Section 2.2 and (ii) 1/500 of the cross-section web thickness $t_{\mathrm{w}}$, as adopted by dos Santos et al. [37] for stainless steel Isection members under internal one-flange and internal two-flange loadings. Mean $F_{\mathrm{u}, \mathrm{FE}} / F_{\mathrm{u}, \mathrm{Test}}$ values close to unity with a low coefficient of variation $(\mathrm{COV})$ were obtained for the case of the measured imperfection amplitudes, while a similar mean value but with higher scatter was obtained when the imperfection amplitude of $t_{\mathrm{w}} / 500$ was employed. The predictions of displacements at ultimate load 
were somewhat more scattered, as is typically the case in problems of this nature where the loaddisplacement curves exhibit a prolonged 'flattered' path in the region of the ultimate load [37, 46]; nonetheless, satisfactory results were achieved with an imperfection amplitude of $t_{\mathrm{w}} / 500$ and this value was therefore adopted in the parametric studies described in the following subsection.

\subsection{PARAMETRIC STUDIES}

Parametric studies were performed to investigate the influence of key parameters on the ultimate capacity of welded stainless steel I-sections under end-one-flange (EOF) loading. In these studies, the measured material properties of the I $140 \times 140 \times 10 \times 12$ specimen were adopted, together with an initial geometric imperfections in a form of the first buckling mode shape, with an amplitude of $t_{\mathrm{w}} / 500$. All the modelled cross-sections had a flange width $b_{\mathrm{f}}$ of $100 \mathrm{~mm}$, a flange thickness $t_{\mathrm{f}}$ of either $15 \mathrm{~mm}$ or $20 \mathrm{~mm}$, a web height $h_{\mathrm{w}}$ of either $550 \mathrm{~mm}$ or $650 \mathrm{~mm}$ and a loading plate length $s_{1}-$ see Fig. $10-$ of either $100 \mathrm{~mm}$ or $300 \mathrm{~mm}$. The distance between the web stiffener and the bearing plate $b$ was set equal to 1.5 times the web height (i.e. either $b=780 \mathrm{~mm}$ or $b=975 \mathrm{~mm}$ ). A member span $L$ equal to twice the distance between the free member end and the mid-length of the loading plate was adopted, i.e. $L=2 \times\left(b+s_{s}+c+s_{1} / 2\right)$. The web thickness $t_{\mathrm{w}}$, the bearing length $s_{\mathrm{s}}$ and the distance between the bearing plate and the member end $c$ were varied to cover a similar range of ratios of parameters as considered in previous studies on carbon steel members under end-one-flange loading conditions [3436]. The lateral displacement (U1) of the top flange at the member end was restrained in order to reproduce the conditions assumed in the current European design formulae [50].

\subsubsection{INFLUENCE OF BEARING LENGTH}

The influence of bearing length $s_{\mathrm{s}}$ on the ultimate resistance of the modelled I-section members under EOF loading is shown in Fig. 13. On the horizontal axis, the bearing length $s_{\mathrm{s}}$ is normalized by the web height $h_{\mathrm{w}}$. The ultimate load $F_{\mathrm{u}}$ is plotted on the vertical axis. Only models with the bearing plate positioned at the free member end (i.e. $c=0$ ) were considered herein. For all web slenderness values, 
the ultimate load may be seen to increase almost linearly with increasing bearing length, due to the load being spread over a larger region of the web.

\subsubsection{INFLUENCE OF WEB SLENDERNESS}

The influence of web slenderness on the ultimate resistance of the modelled I-section members subjected to EOF loading for different bearing lengths is shown in Fig. 14. The web slenderness is plotted on the horizontal axis while the ultimate load $F_{\mathrm{u}}$ is plotted on the vertical axis at two different scales in (a) and (b). Again only models with the bearing plate positioned at the free member end (i.e. $c=0$ ) were considered. The results show a reduction in ultimate load for increasing web slenderness; the rate of reduction is greater for lower web slenderness.

\subsubsection{INFLUENCE OF THE DISTANCE BETWEEN THE BEARING PLATE AND THE MEMBER END}

The influence of the distance between the bearing plate and the free member end $c$ on the ultimate resistance of the modelled I-section members under EOF loading is shown in Fig. 15. The bearing length $s_{\mathrm{s}}$ was kept constant at $15 \mathrm{~mm}$. The ultimate load generally increases as the distance $c$ increases due to the load being able to spread into the member to both sides of the bearing plate and hence over a larger region of the web.

\section{ASSESSMENT OF EXISTING DESIGN RULES}

In this section, the methods set out in EN 1993-1-4 [50] and AISC Design Guide 27 [41] for the design of stainless steel members under concentrated transverse loading are assessed. The accuracy of the design provisions is evaluated by comparing the experimental (from both the present and existing studies [38]) and numerical failure loads $F_{\mathrm{u}}$ with the failure loads predicted by the specification $F_{\mathrm{u}, \text { pred. }}$ A value of $F_{\mathrm{u}} / F_{\mathrm{u} \text {,pred }}$ greater than unity indicates a safe-sided design prediction. Measured (or modelled) material and geometric properties were used in all the comparisons and all partial safety factors were set equal to unity. Note that only results where the critical design check was resistance to concentrated loading are shown in the comparisons presented in this section. The tests where the critical design check was not resistance to concentrated loading, but combined bending plus shear, are indicated with 
an asterisk in Table 2; these specimens generally exhibited a higher degree of bending and shear deformations, as can be seen in Fig. 4. Hence, overall data from 10 end-one-flange loading tests, 6 from the current study (i.e. those where EOF loading failure was critical) and 4 from previous investigations [38], were considered.

\subsection{EN 1993-1-4 (EC3)}

EN 1993-1-4 [50] adopts the carbon steel design rules described in EN 1993-1-5 [40] for stainless steel members under end-one-flange loading. The design resistance to local failure under concentrated transverse loading $F_{\mathrm{Rd}}$ is determined using Eq. (3), where $f_{\mathrm{yw}}$ is the web $0.2 \%$ proof stress, $t_{\mathrm{w}}$ is the web thickness and $L_{\text {eff }}$ is the effective length, which is given by the product of the effective loaded length $l_{\mathrm{y}}$ from Eqs. (4)-(6) and the reduction factor $\chi_{\mathrm{F}}$. The method adopted for the determination of the effective loaded length $l_{\mathrm{y}}$ is based on the original plastic mechanism proposed by Voss [51] and further developed by Lagerqvist and Johansson [52].

$$
\begin{aligned}
& F_{\mathrm{Rd}}=f_{\mathrm{yw}} L_{\mathrm{eff}} t_{\mathrm{w}} \text { where } L_{\mathrm{eff}}=\chi_{\mathrm{F}} l_{\mathrm{y}} \\
& l_{\mathrm{y}}=\min \left(l_{y, 1}, l_{y, 2}, l_{y, 3}\right) \\
& l_{\mathrm{y}, 1}=s_{\mathrm{s}}+2 t_{\mathrm{f}}\left(1+\sqrt{m_{1}+m_{2}}\right), l_{\mathrm{y}, 2}=l_{\mathrm{e}}+t_{\mathrm{f}} \sqrt{\frac{m_{1}}{2}+\left(\frac{l_{\mathrm{e}}}{t_{\mathrm{f}}}\right)^{2}+m_{2}} \text { and } l_{\mathrm{y}, 3}=l_{\mathrm{e}}+t_{\mathrm{f}} \sqrt{m_{1}+m_{2}} \\
& \text { where } m_{1}=\frac{f_{\mathrm{yf}} b_{\mathrm{f}}}{f_{\mathrm{yw}} t_{\mathrm{w}}}, m_{2}=\mid \begin{array}{l}
0.02\left(\frac{h_{\mathrm{w}}}{t_{\mathrm{f}}}\right)^{2} \text { for } \bar{\lambda}_{\mathrm{F}}>0.5 \text { and } l_{\mathrm{e}}=\frac{k_{\mathrm{F}} E t_{\mathrm{w}}^{2}}{2 f_{\mathrm{yw}} h_{\mathrm{w}}} \leq s_{\mathrm{s}}+c \\
0 \text { for } \bar{\lambda}_{\mathrm{F}} \leq 0.5
\end{array}
\end{aligned}
$$

The reduction factor $\chi_{\mathrm{F}}$, determined from Eq. (7), is a function of the slenderness parameter $\bar{\lambda}_{\mathrm{F}}$, which is equal to the square root of the ratio of the plastic load, given by Eq. (8), to the elastic buckling load $F_{\text {cr }}$ of the member under concentrated force. The elastic buckling load $F_{\text {cr }}$ is determined from Eq. (9) where $k_{\mathrm{F}}$ is the buckling coefficient for EOF loading.

$$
\begin{aligned}
& \chi_{\mathrm{F}}=\frac{0.5}{\bar{\lambda}_{\mathrm{F}}} \leq 1.0 \text { where } \bar{\lambda}_{\mathrm{F}}=\sqrt{\frac{F_{\mathrm{y}}}{F_{\mathrm{cr}}}} \\
& F_{\mathrm{y}}=l_{\mathrm{y}} t_{\mathrm{w}} f_{\mathrm{yw}} \\
& F_{\mathrm{cr}}=0.9 k_{\mathrm{F}} E \frac{t_{\mathrm{w}}^{3}}{h_{\mathrm{w}}} \text { where } k_{\mathrm{F}}=2+6\left(\frac{s_{\mathrm{s}}+c}{h_{\mathrm{w}}}\right)^{2} \leq 6
\end{aligned}
$$


A quantitative evaluation of the accuracy of EN 1993-1-4 (i.e. EN 1993-1-5) for members under EOF loading (where resistance to concentrated loading was the critical design check) can be found in Table 5, which shows for all studied cases a mean value for $F_{\mathrm{u}} / F_{\mathrm{u}, \mathrm{EC} 3}$ of 1.59 with a coefficient of variation $(\mathrm{COV})$ of 0.24 . The table also shows a general increasing trend of $F_{\mathrm{u}} / F_{\mathrm{u}, \mathrm{EC} 3}$ with reducing web slenderness values (e.g. the mean value of $F_{\mathrm{u}} / F_{\mathrm{u}, \mathrm{EC} 3}=2.35$ for $h_{\mathrm{w}} / t_{\mathrm{w}}<20$ in comparison to $F_{\mathrm{u}} / F_{\mathrm{u}, \mathrm{EC} 3}=$ 1.32 for $h_{\mathrm{w}} / t_{\mathrm{w}} \geq 110$ ). The overly-conservative results in the low $h_{\mathrm{w}} / t_{\mathrm{w}}$ range, also observed in Fig. 17 , can be attributed to the neglect of the pronounced strain hardening of stainless steel, which is more influential on the behaviour of the stockier webs. Fig. 16 shows a comparison between the test/FE results and the EC3 strength curve for concentrated transverse loading, i.e. the reduction factor $\chi_{\mathrm{F}}$, given by Eq. (7) versus the non-dimensional slenderness $\bar{\lambda}_{\mathrm{F}}$. The EOF tests on welded stainless steel I-sections of Sélen [38] are also included in this figure. Conservatism in the current code provisions is visible over the full slenderness range, and is particularly pronounced for stocky cross-sections.

\subsection{AISC DESIGN GUIDE 27}

AISC Design Guide 27 [41] for the design of stainless steel hot-rolled and welded I-section members refers to the provisions for carbon steel members under concentrated transverse loading given in ANSI/AISC 360-16 [53]. The design resistance of members subjected to a single load at the free member end (i.e. end-one-flange loading) is obtained by the evaluation of two limit states: (i) web local yielding, and (ii) web local crippling, both of which are presented in Table 4. The design provisions are evaluated by comparing the experimental or numerical failure loads $F_{\mathrm{u}}$ with the design resistance $F_{\mathrm{u}, \mathrm{AISC}}$ taken as the minimum of the values determined for the aforementioned limit states see Table 5. Based on the full range of experimental and numerical data (where resistance to concentrated loading was the critical design check), a mean value of $F_{\mathrm{u}} / F_{\mathrm{u}, \mathrm{AISC}}$ of 1.86 with a coefficient of variation $(\mathrm{COV})$ of 0.50 was obtained. As for EC3, higher ratios of $F_{\mathrm{u}} / F_{\mathrm{u}, \mathrm{AISC}}$ are observed for the stockier sections, as shown in Table 5 and Fig. 17, ranging from a mean value of 
$F_{\mathrm{u}} / F_{\mathrm{u}, \mathrm{AISC}}=2.84$ for $20 \leq h_{\mathrm{w}} / t_{\mathrm{w}}<40$ to $F_{\mathrm{u}} / F_{\mathrm{u}, \mathrm{AISC}}=1.28$ for $80 \leq h_{\mathrm{w}} / t_{\mathrm{w}}<110$, and are again attributed to the neglect of strain hardening in the design calculations. The high degree of conservatism in the AISC Design Guide 27/ANSI/AISC 360-16 resistance predictions to local failure under other types of concentrated transverse loading has also been observed in previous research [37, 54]. For very slender webs, lower ratios of $F_{\mathrm{u}} / F_{\mathrm{u} \text {,AISC }}$ are observed (i.e. for $110 \leq h_{\mathrm{w}} / t_{\mathrm{w}}<245$, the mean value of $F_{\mathrm{u}} / F_{\mathrm{u}, \text { AISC }}$ $=0.63$ ), signifying overpredictions of the ultimate resistance by the design resistance equations. This apparent shortcoming may relate to the fairly limited range of test data $[1,35]$ upon which the design rules were developed $\left(40 \lesssim h_{\mathrm{w}} / t_{\mathrm{w}} \lesssim 60\right)$ and to the fact that the AISC web compression buckling checks apply only when a pair of exactly adjacent compressive concentrated forces exists.

\subsection{DISCUSSION}

An evaluation of the current European and North American design provisions for stainless steel members under end-one-flange loading (EOF) has been presented in Sections 4.1 and 4.2, respectively. In the low web slenderness range, both sets of resistance functions resulted in conservative capacity predictions since no account is taken of strain hardening. In the high web slenderness range, the European design provisions remain conservative while the North American design provisions lead to overpredictions of resistance. Overall, there is clear scope for the development of improved design equations for the resistance of stainless steel members under end-one-flange loading over the entire slenderness range.

\section{CONCLUSIONS}

An experimental and numerical study of welded stainless steel I-beams under concentrated end-oneflange (EOF) loading has been presented. A total of 10 experiments and 90 finite element simulations were carried out, covering a wide range of the key driving parameters in the structural response. Both the numerical and test results were used to evaluate the accuracy of the European and North American design provisions. The results showed that the existing design procedures are generally safe-sided but overly conservative for members with stocky webs due to the influence of strain hardening being omitted from the resistance functions. The findings of this study illustrate the need for the development 
of new design rules for stainless steel beams under concentrated end-one-flange loading, which is the focus of ongoing work.

\section{ACKNOWLEDGMENTS}

The authors would like to thank Montanstahl AG for providing the test specimens for the project. The contribution of Andy Pullen, Gordon Herbert, Les Clark and Mike Drake in the experimental part of this work as well as the financial support of the Brazilian National Council for Scientific and Technological Development (CNPq, Brazil) are also gratefully acknowledged. 


\section{REFERENCES}

[1] Graham, J.D., Sherbourne, A.N., Kabbaz, R.N., and Jensen, C.D. "Welded interior beam-tocolumn connections". American Institute of Steel Construction (AISC), 1959.

[2] Chacón, R., Herrera, J., and Fargier-Gabaldon, L. "Improved design of transversally stiffened steel plate girders subjected to patch loading". Engineering Structures, 150 (1): p. 774-785, 2017.

[3] Macdonald, M., Heiyantuduwa, M.A., Harrison, D.K., Bailey, R., and Rhodes, J. "Literature review of web crippling behaviour". in 2nd Scottish Conference for Postgraduate Researchers of the Built and Natural Environment (PRoBE 2005), Rotterdam (Netherlands): In-house Publishing, 2005.

[4] Mijušković, O., Branislav, Ć., Šćepanović, B., and Žugić, L. "Analytical model for buckling analysis of the plates under patch and concentrated loads". Thin-Walled Structures, 101: p. 2642, 2016.

[5] Bakker, M.C.M. "Yield line analysis of post-collapse behaviour of thin-walled steel members". Heron, 35 (3), 1990.

[6] Natário, P., Silvestre, N., and Camotim, D. "Localized web buckling analysis of beams subjected to concentrated loads using GBT". Thin-Walled Structures, 61: p. 27-41, 2012.

[7] dos Santos, G.B., Gardner, L., and Kucukler, M. "A method for the numerical derivation of plastic collapse loads". Thin-Walled Structures, 124: p. 258-277, 2018.

[8] Winter, G. and Pian, R.H.J. "Crushing strength of thin steel webs". Engineering Experiment Station, Bulletin No 35 (Part 1): p. 1-24, 1946.

[9] Yu, W.W. and Hetrakul, N. "Webs for cold formed steel flexural members structural behavior of beam webs subjected to web crippling and a combination of web crippling and bending". University of Missouri-Rolla, 1978.

[10] Gerges, R.R. and Schuster, R.M. "Web crippling of single web cold formed steel members subjected to end one-flange loading". in Fourteenth International Specialty Conference on Cold-Formed Steel Structures: Recent Research and Developments in Cold-Formed Steel Design and Construction, October 15, 1998 - October 16, 1998, St. Louis, MO, United states: University of Missouri-Rolla, 1998.

[11] Young, B. and Hancock, G.J. "Design of cold-formed channels subjected to web crippling". Journal of Structural Engineering ASCE, 127 (10): p. 1137-1144, 2001.

[12] Young, B. and Hancock, G.J. "Cold-formed steel channels subjected to concentrated bearing load". Journal of Structural Engineering ASCE, 129 (8): p. 1003-1010, 2003. 
[13] Wing, B.A. and Schuster, R.M. "Web crippling of decks subjected to two flange loading". in 6th International Specialty Conference on Cold-Formed Steel Structures, Missouri University of Science and Technology, 1982.

[14] Li, H.-T. and Young, B. "Tests of cold-formed high strength steel tubular sections undergoing web crippling". Engineering Structures, 141: p. 571-583, 2017.

[15] Bhakta, B.H., LaBoube, R.A., and Yu, W.W. "The effect of flange restraint on web crippling strength". Civil Engineering Study 92-1, University of Missouri-Rolla, 1992.

[16] Cain, D.E., LaBoube, R.A., and Yu, W.W. "The effect of flange restraint on web crippling strength of cold-formed steel Z- and I- sections". Civil Engineering Study 95-2, University of Missouri-Rolla, 1995.

[17] Janarthanan, B., Mahendran, M., and Gunalan, S. "Bearing capacity of cold-formed unlipped channels with restrained flanges under EOF and IOF load cases". Steel Construction, 8 (3): p. 146-154, 2015.

[18] Lian, Y., Uzzaman, A., Lim, J.B.P., Abdelal, G., Nash, D., and Young, B. "Effect of web holes on web crippling strength of cold-formed steel channel sections under end-one-flange loading condition - Part I: Tests and finite element analysis". Thin-Walled Structures, 107: p. 443-452, 2016.

[19] Talja, A. and Hradil, P. "Structural Applications of Ferritic Stainless Steels (SAFSS) WP2: Structural performance of steel members - Model calibration tests". Report of the SAFSS Project - Structural Applications of Ferritic Stainless Steels, VTT-R-06130-12, VTT Technical Research Centre of Finland, 2012.

[20] Korvink, S.A., van der Berg, G.J., and van der Merwe, P. "Web crippling of stainless steel cold-formed beams". Journal of Constructional Steel Research, 34: p. 225-248, 1995.

[21] Zhou, F. and Young, B. "Cold-formed stainless steel sections subjected to web crippling". Journal of Structural Engineering ASCE, 132 (1): p. 134-144, 2006.

[22] Zhou, F. and Young, B. "Cold-formed high-strength stainless steel tubular sections subjected to Web crippling". Journal of Structural Engineering ASCE, 133 (3): p. 368-377, 2007.

[23] Zhou, F. and Young, B. "Experimental and numerical investigations of cold-formed stainless steel tubular sections subjected to concentrated bearing load". Journal of Constructional Steel Research, 63 (11): p. 1452-66, 2007.

[24] Zhou, F. and Young, B. "Experimental Investigation of Cold-Formed High-Strength Stainless Steel Tubular Members Subjected to Combined Bending and Web Crippling". Journal of Structural Engineering ASCE, 133 (7): p. 1027-1034, 2007.

[25] Li, H.-T. and Young, B. "Cold-formed ferritic stainless steel tubular structural members subjected to concentrated bearing loads". Engineering Structures, 145: p. 392-405, 2017. 
[26] Cai, Y. and Young, B. "Web crippling of lean duplex stainless steel tubular sections under concentrated end bearing loads". Thin-Walled Structures, 139: p. 29-39, 2019.

[27] Bock, M., Arrayago, I., Real, E., and Mirambell, E. "Study of web crippling in ferritic stainless steel cold formed sections". Thin-Walled Structures, 69: p. 29-44, 2013.

[28] Bock, M. and Real, E. "Strength curves for web crippling design of cold-formed stainless steel hat sections". Thin-Walled Structures, 85: p. 93-105, 2014.

[29] Yousefi, A.M., Lim, J.B.P., Uzzaman, A., and Clifton, G.C. "Numerical study of web crippling strength in cold-formed austenitic stainless steel lipped channels with web openings subjected to interior-two-flange loading". in 11th Pacific Structural Steel Conference, Shanghai, 2016.

[30] Tryland, T., Hopperstad, O.S., and Langseth, M. "Finite-element modeling of beams under concentrated loading". Journal of Structural Engineering, 127 (2): p. 176-185, 2001.

[31] Tryland, T., Hopperstad, O.S., and Langseth, M. "Steel girders subjected to concentrated loading - Validation of numerical simulations". Journal of Constructional Steel Research, 50: p. 199-216, 1999.

[32] Ketchum, M.S. and Draffin, J.O. "Strength of light I beams". 29, Bulletin No 241, University of Illinois, 1932.

[33] Lyse, I. and Godfrey, H.J. "Web crippling of steel beams". Paper 1148, Fritz Laboratory Reports, 1933.

[34] Bamm, D., Lindner, J., and Voß, R.-P. "Traglastversuche an ausgesteiften Tragerauflagern (Tests on stiffened support bearings, in German)". Stahlbau, 52 (10): p. 296-300, 1983.

[35] Elgaaly, M. and Salkar, R.K. "Web crippling under local compressive edge loading". in 4th National Steel Construction Conference, Washington, USA: AISC, 1991.

[36] Lagerqvist, O. "Patch loading - Resistance of steel girders to concentrated forces". Division of Steel Structures, Lulea University of Technology, PhD thesis (1994:159D), 1995.

[37] dos Santos, G.B., Gardner, L., and Kucukler, M. "Experimental and numerical study of stainless steel I-sections under concentrated internal one-flange and internal two-flange loading". Engineering Structures, 175: p. 355-370, 2018.

[38] Sélen, E. "Work package 3.5 - Final Report - Web crippling". Report to the ECSC Project Development of the use of stainless steel in construction. Contract no. 7210-SA/903, Lulea University of Technology, 2000.

[39] AISI S100-12. North American Specification for the Design of Cold-Formed Steel Structural Members, American Iron and Steel Institute, Washington D.C., 2012.

[40] EN 1993-1-5:2006. Eurocode 3: Design of steel structures - Part 1-5: Plated structural elements, European Committee for Standardization (CEN), Brussels, 2006. 
[41] AISC Steel Design Guide 27. Structural Stainless Steel, American Institute of Steel Construction, USA, 2013.

[42] EN ISO 13919-1. Welding - Electron and laser beam welded joints - Guidance on quality levels for imperfections - Part 1: Steel, European Committee for Standardization (CEN), Brussels, 1997.

[43] Gardner, L., Bu, Y., and Theofanous, M. "Laser-welded stainless steel I-sections: Residual stress measurements and columns buckling tests". Engineering Structures, 127: p. 536-548, 2016.

[44] EN ISO 6892-1:2009. Metallic materials - Tensile testing - Part 1: Method of test at ambient temperature, European Committee for Standardization (CEN), Brussels, 2009.

[45] Schafer, B.W. and Peköz, T. "Computational modeling of cold-formed steel: characterizing geometric imperfections and residual stresses". Journal of Constructional Steel Research, 47: p. 193-210, 1998.

[46] Zhao, O., Gardner, L., and Young, B. "Structural performance of stainless steel circular hollow sections under combined axial load and bending - Part 1: Experiments and numerical modelling". Thin-Walled Structures, 101: p. 231-239, 2016.

[47] DaVis. "Product-Manual DaVis 8.4". LaVision [Software] 2016.

[48] ABAQUS. "Abaqus version 6.14". SIMULIA - Dassault Systèmes [Software] 2014.

[49] Saliba, N. and Gardner, L. "Cross-section stability of lean duplex stainless steel welded Isections". Journal of Constructional Steel Research, 80: p. 1-14, 2013.

[50] EN 1993-1-4:2006+A1:2015. Eurocode 3: Design of steel structures - Part 1.4: General rules - Supplementary rules for stainless steels, European Committee for Standardization (CEN), Brussels, 2006.

[51] Voss, R.-P. "Bemessung von Lasteinleitungssteifen in geschweißten Vollwandträgern (Dimensioning of load-introduction-stiffeners in welded plate girders, in German)". Stahlbau, 56 (4): p. 97-106, 1987.

[52] Lagerqvist, O. and Johansson, B. "Resistance of I-girders to concentrated loads". Journal of Constructional Steel Research, 39 (2): p. 87-119, 1996.

[53] ANSI/AISC 360-16. Specification for structural steel buildings, EUA, 2016.

[54] Menkulasi, F., Farzana, N., Moen, C.D., and Eatherton, M.R. "Revisiting web compression buckling for wide flange sections". in SSRC Annual Stability Conference, Florida, USA, 2016. 


\section{FIGURES}

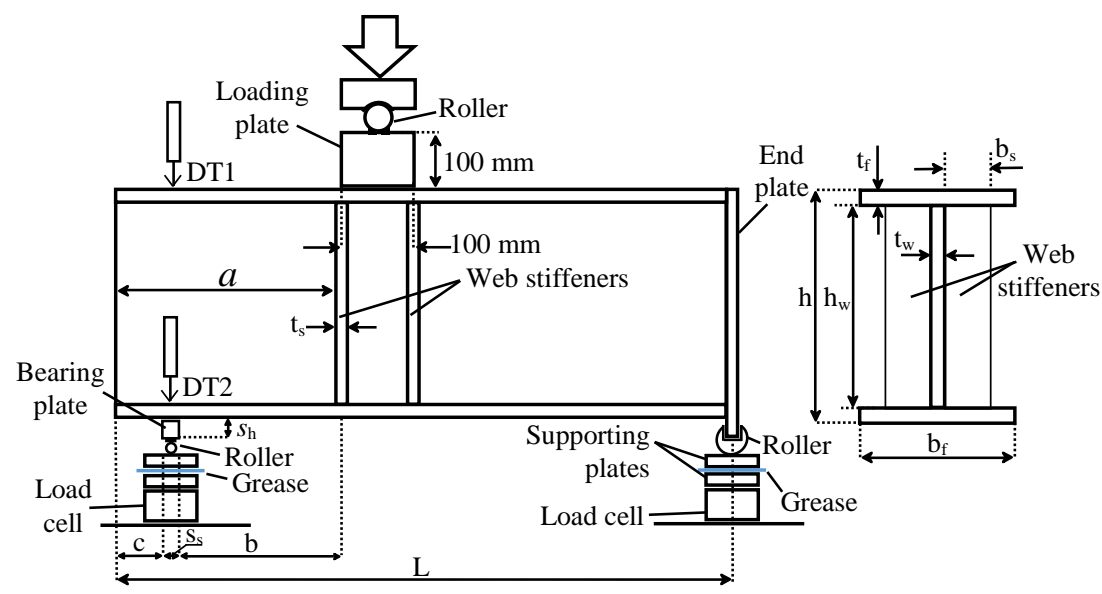

(a) Schematic illustration of setup

Fig. 1. Experimental setup for EOF specimens.

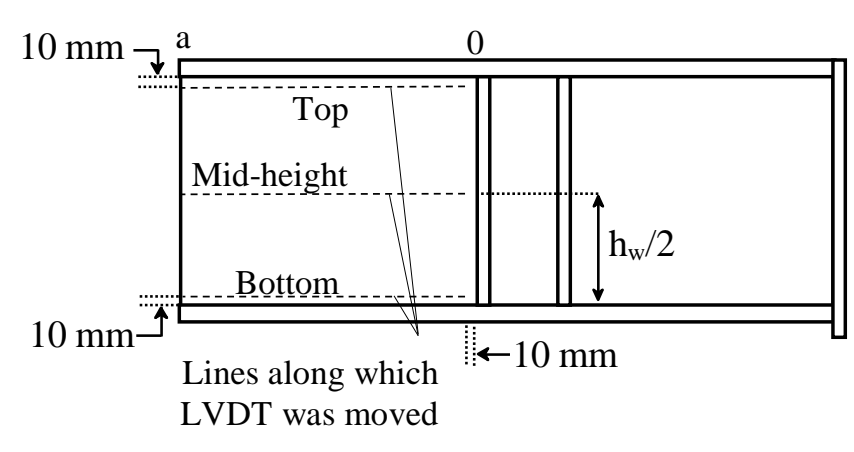

(a) Schematic illustration of setup

Fig. 2. Imperfection measurement setup.

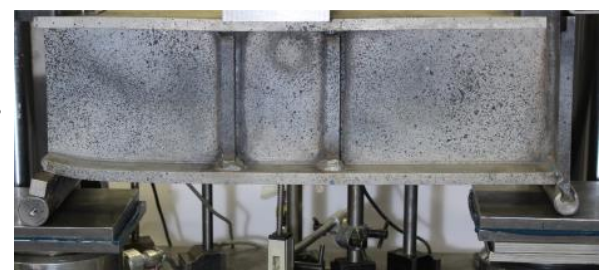

(b) Test setup

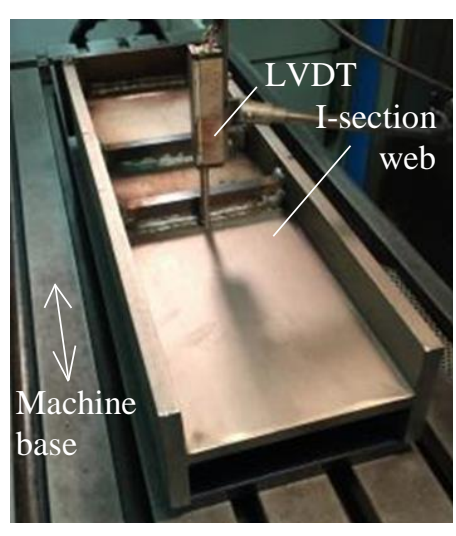

(b) Test setup 


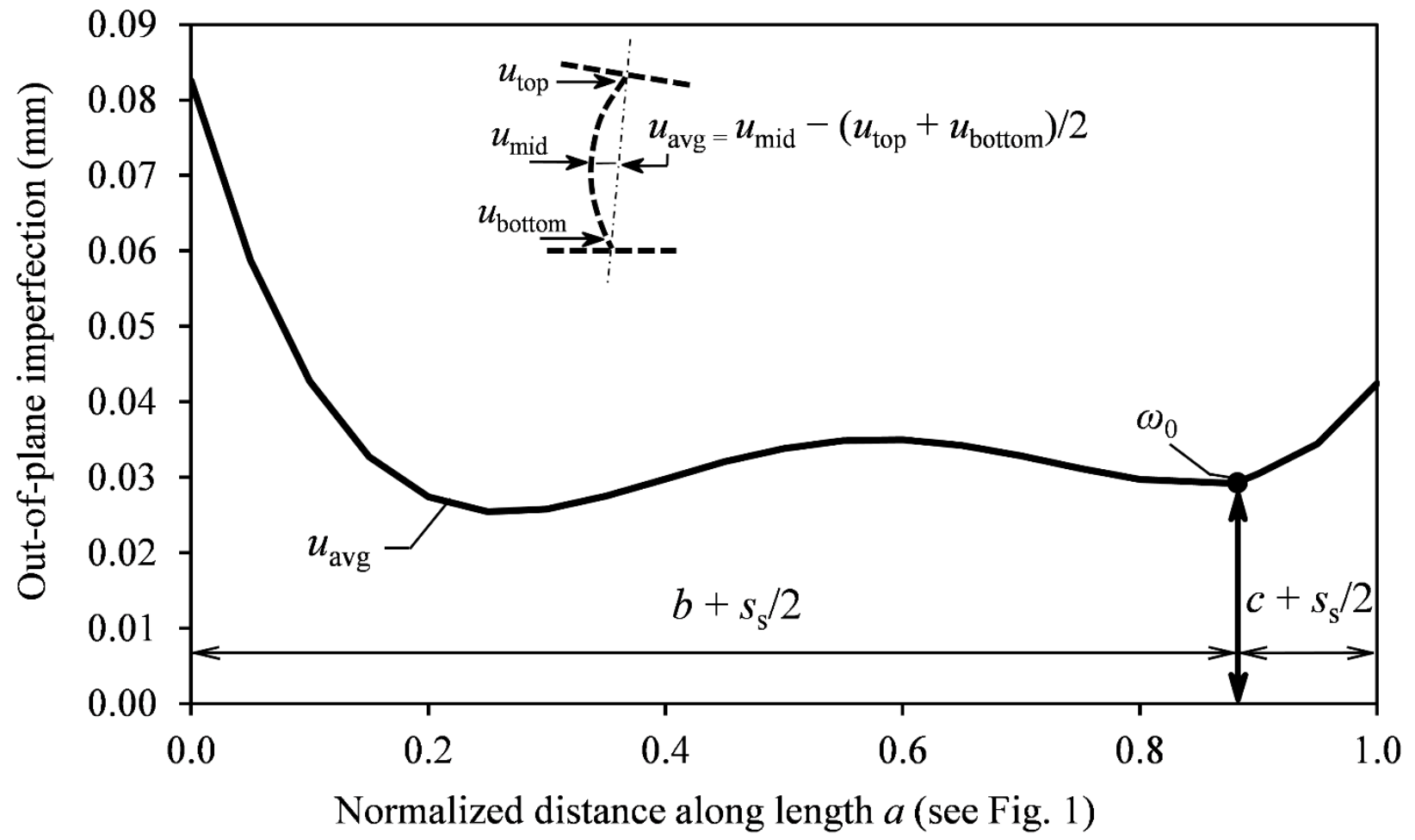

Fig. 3. Measured out-of-plane geometric imperfections $u_{\text {avg }}$ for EOF-h140-b180-ss15-c20 test specimen and definition of $\omega_{0}$.

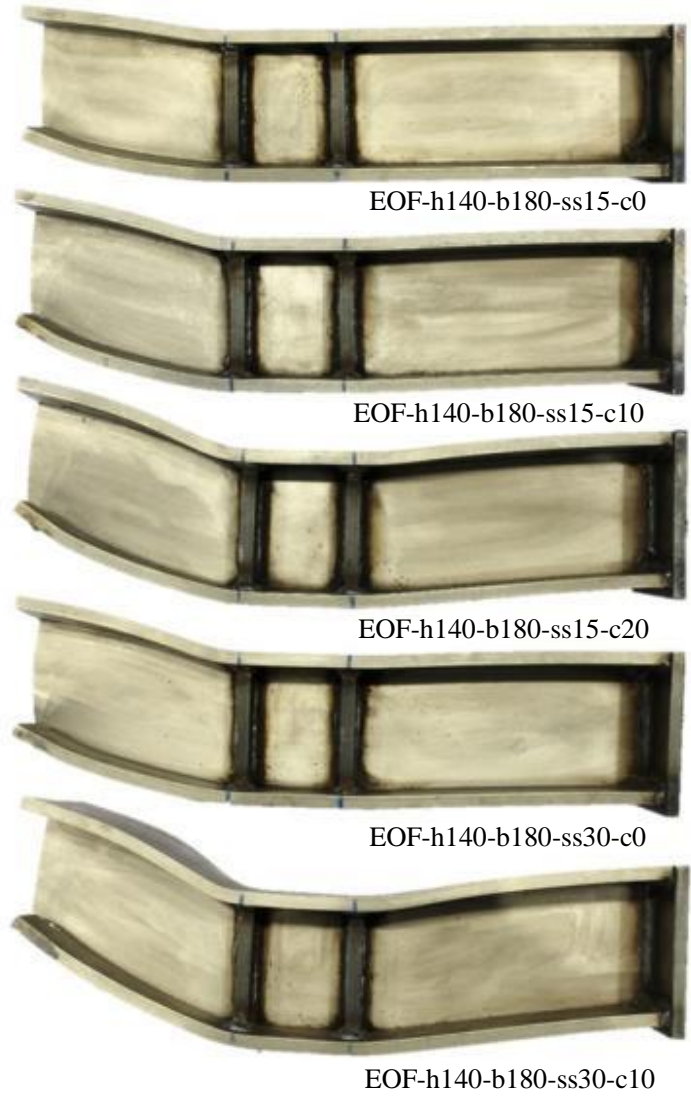

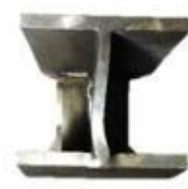
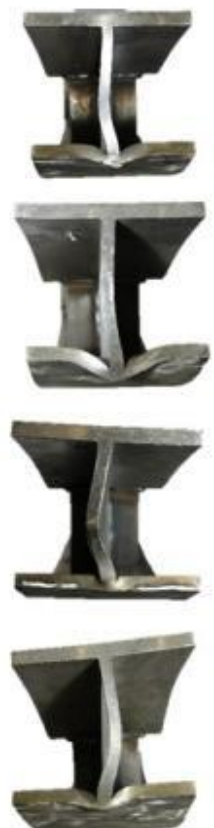
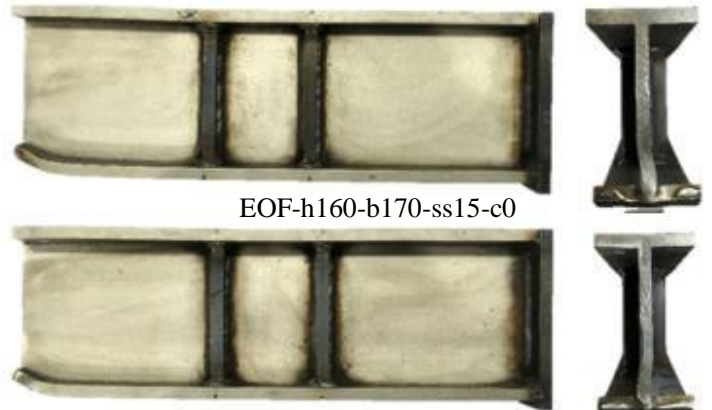

EOF-h160-b180-ss15-c0

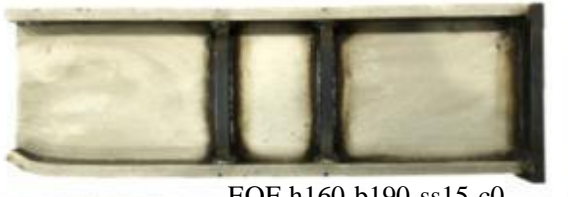

EOF-h160-b190-ss15-c0

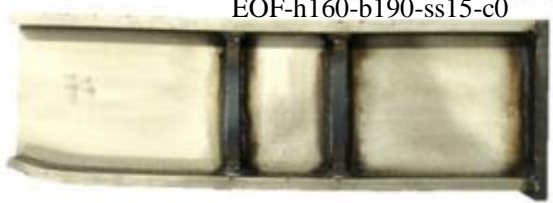

EOF-h160-b200-ss15-c0

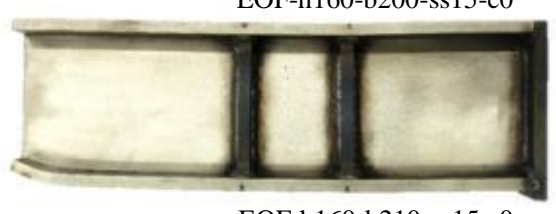

EOF-h160-b210-ss15-s0
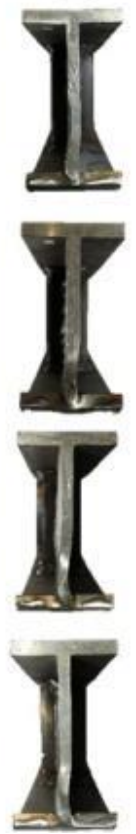

Fig. 4. Failure modes of end-one-flange (EOF) loading test specimens - side and front views. 


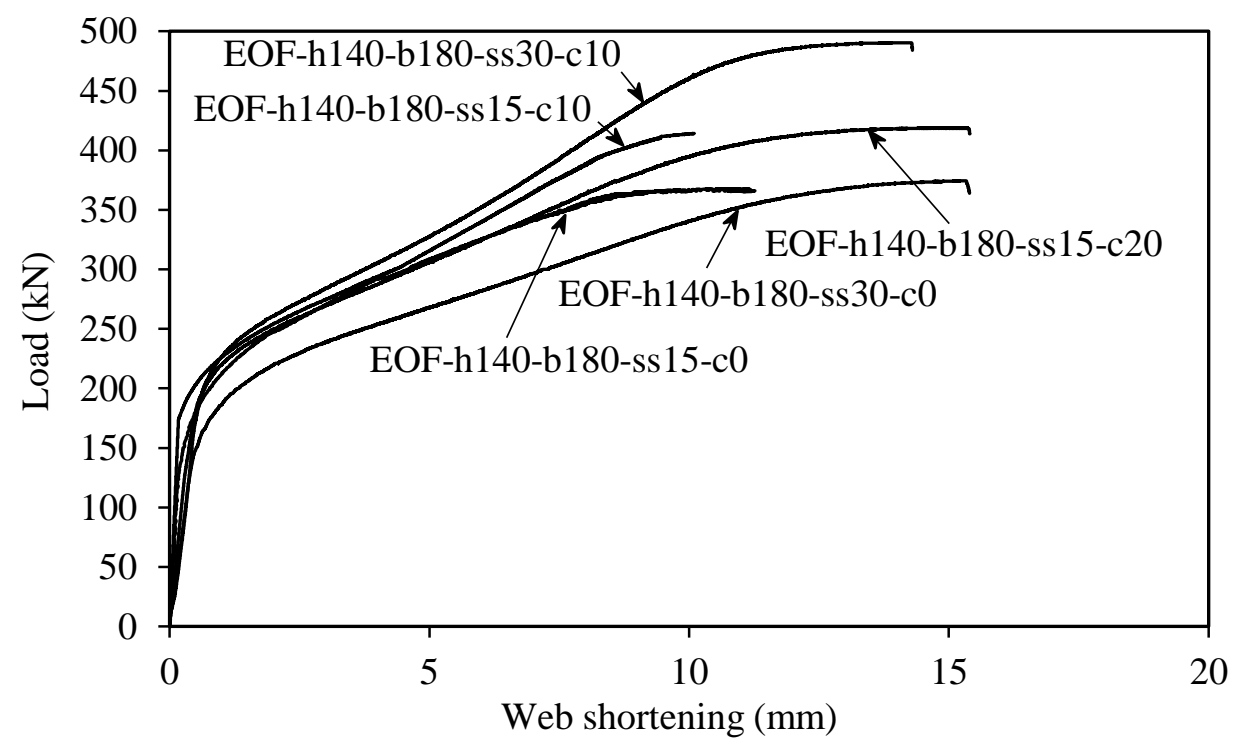

Fig. 5. Load-web shortening response of the tested EOF h140 specimens.

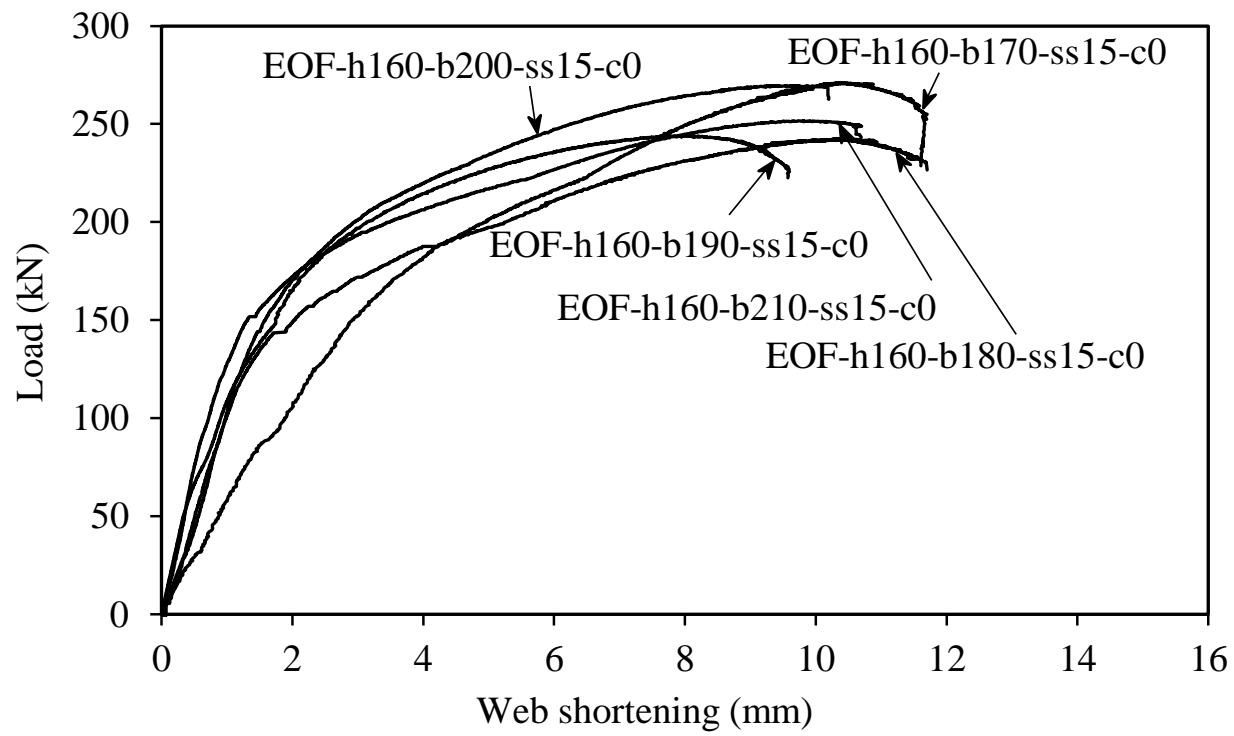

Fig. 6. Load-web shortening response of the tested EOF h160 specimens. 


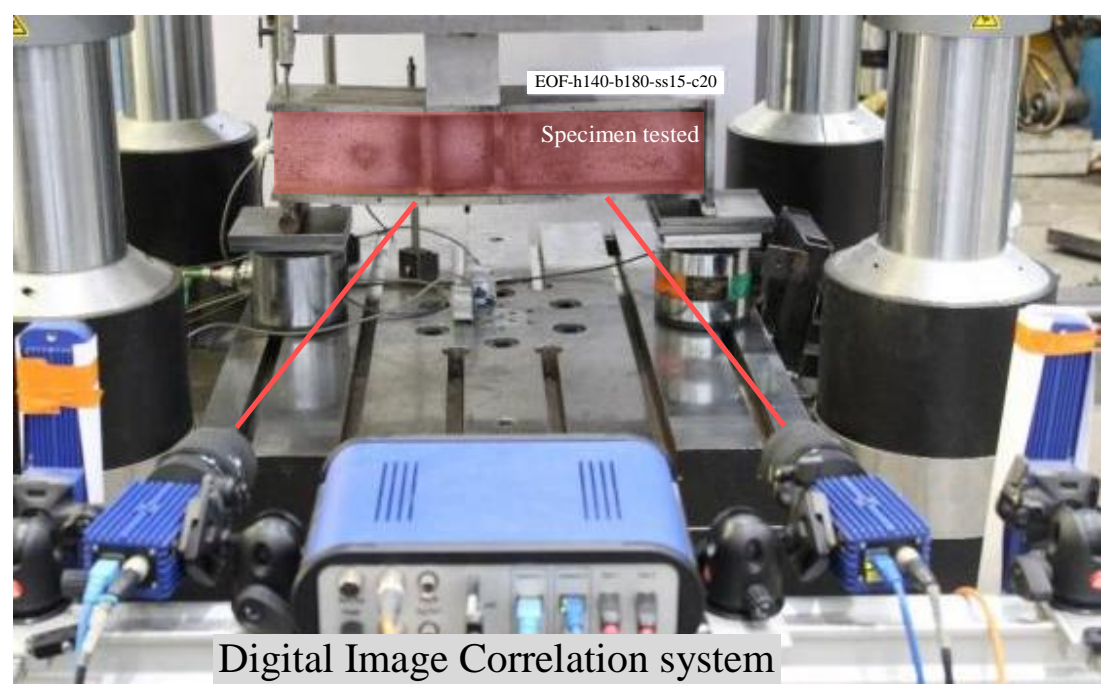

Fig. 7. Set-up of Digital Image Correlation (DIC) system. 


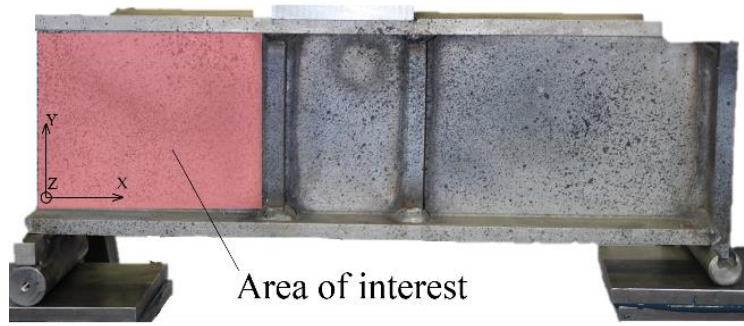

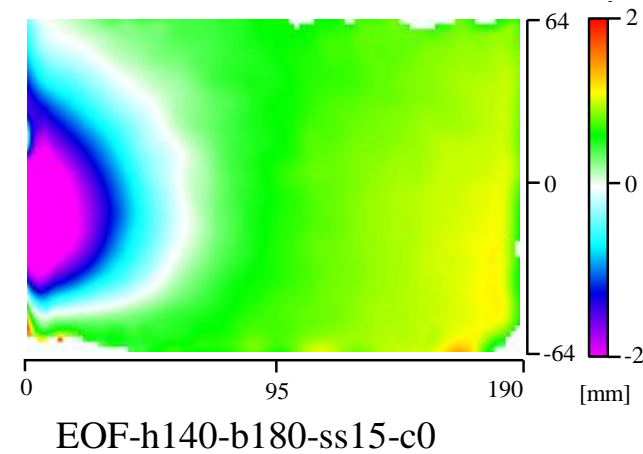
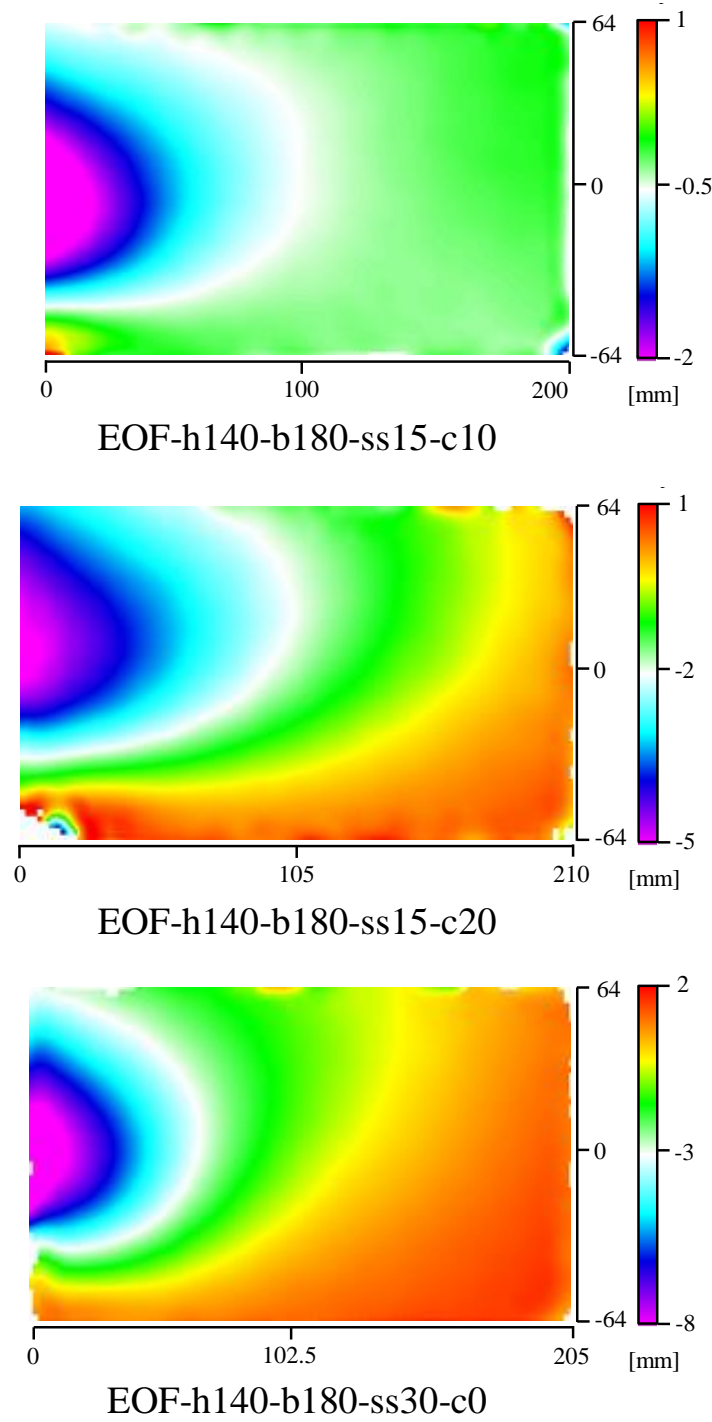
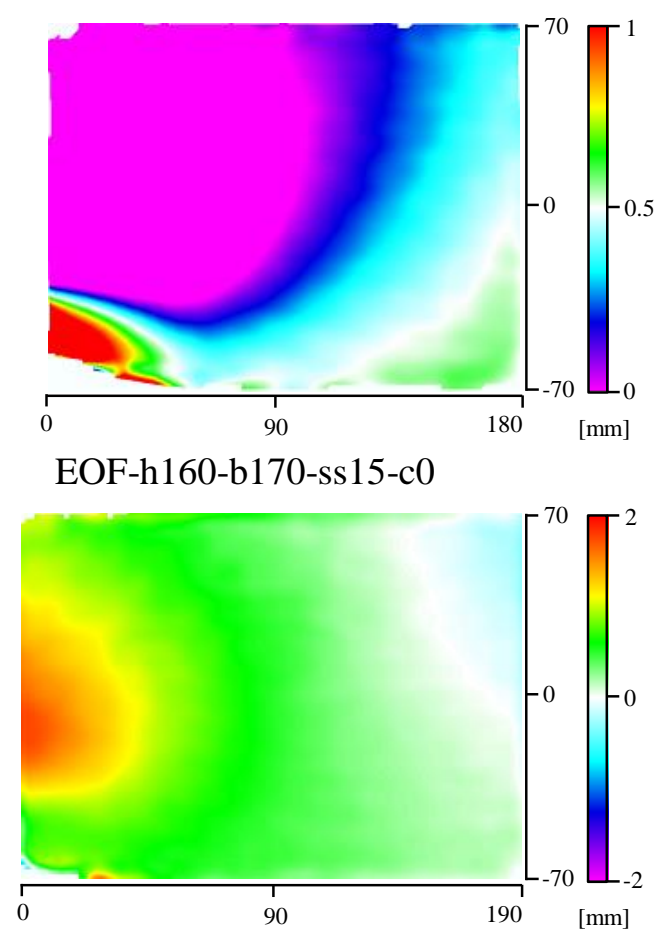

EOF-h160-b180-ss15-c0

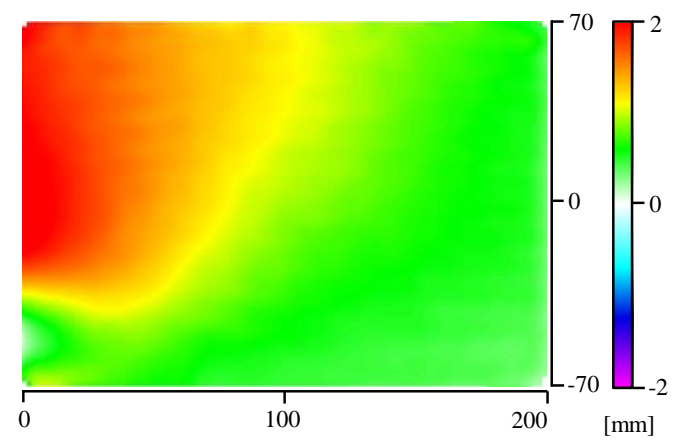

EOF-h160-b190-ss15-c0

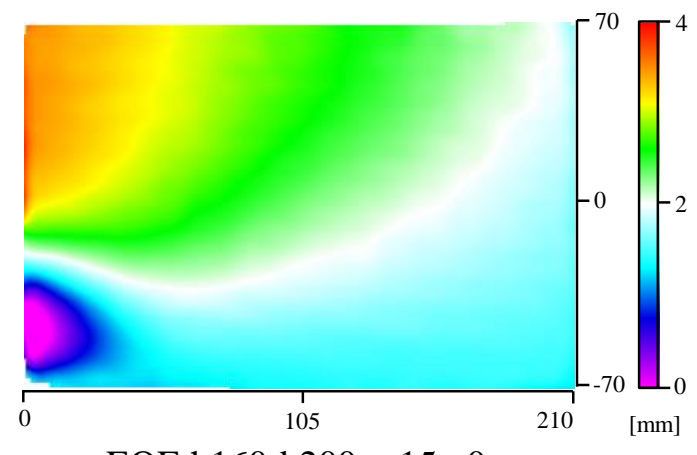

EOF-h160-b200-ss15-c0 


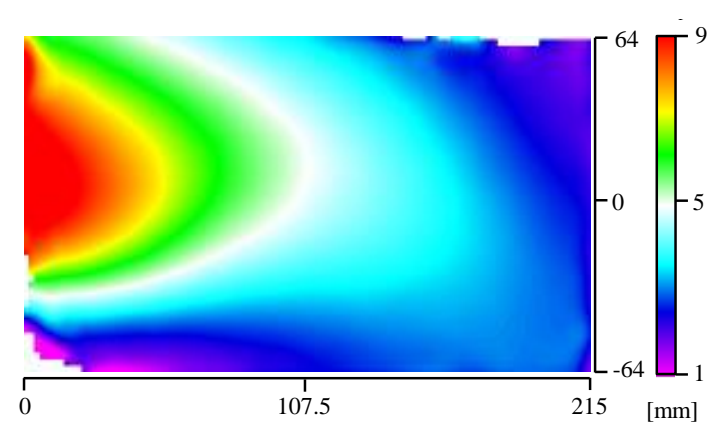

EOF-h140-b180-ss30-c10

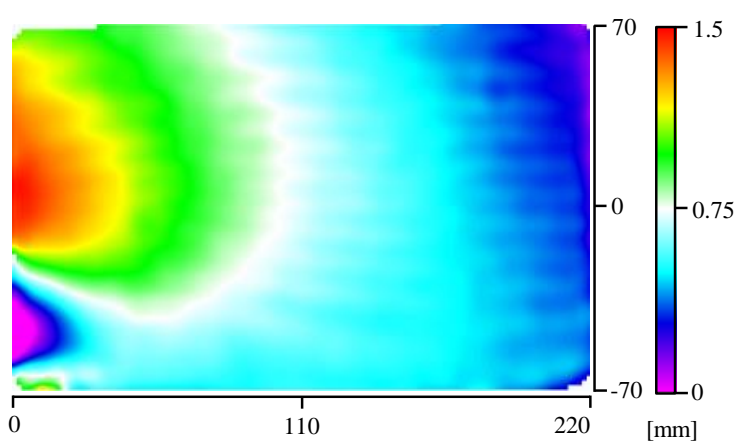

EOF-h160-b210-ss15-c0

Fig. 8. Out-of-plane displacement fields of test specimens obtained at ultimate load using DIC.
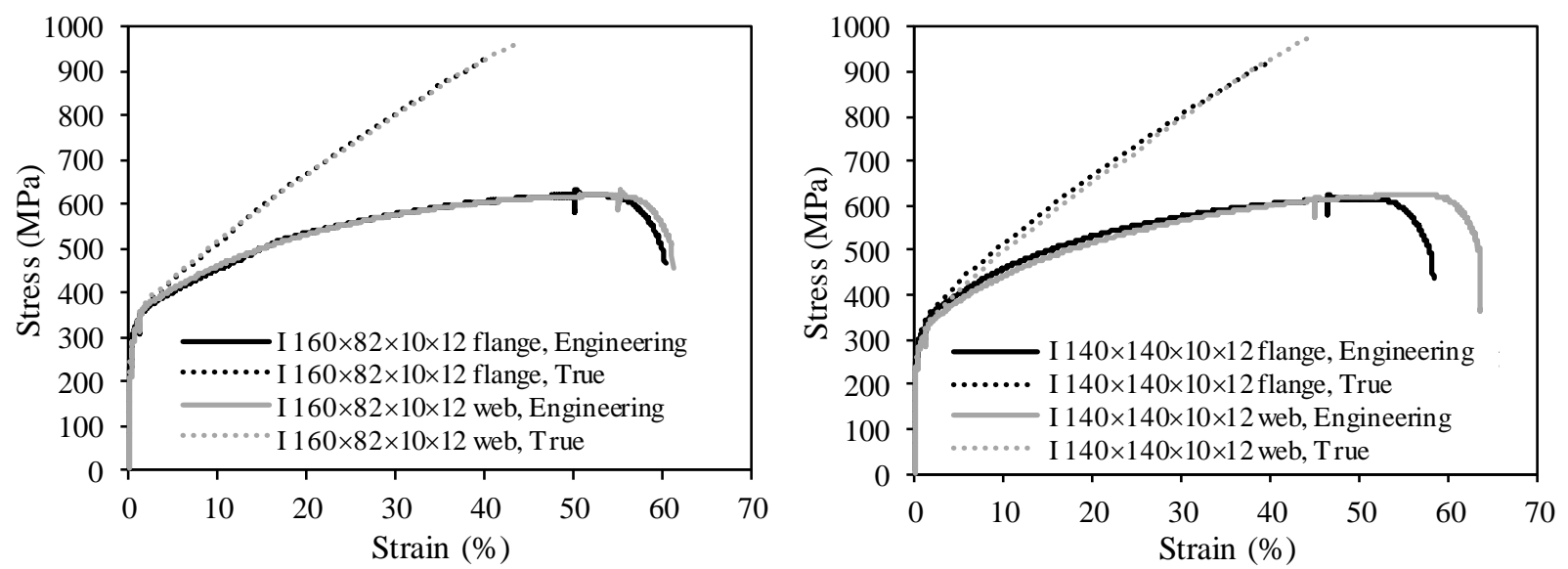

Fig. 9. Engineering and true stress-strain curves for material from tested h160 [37] and h140 specimens.

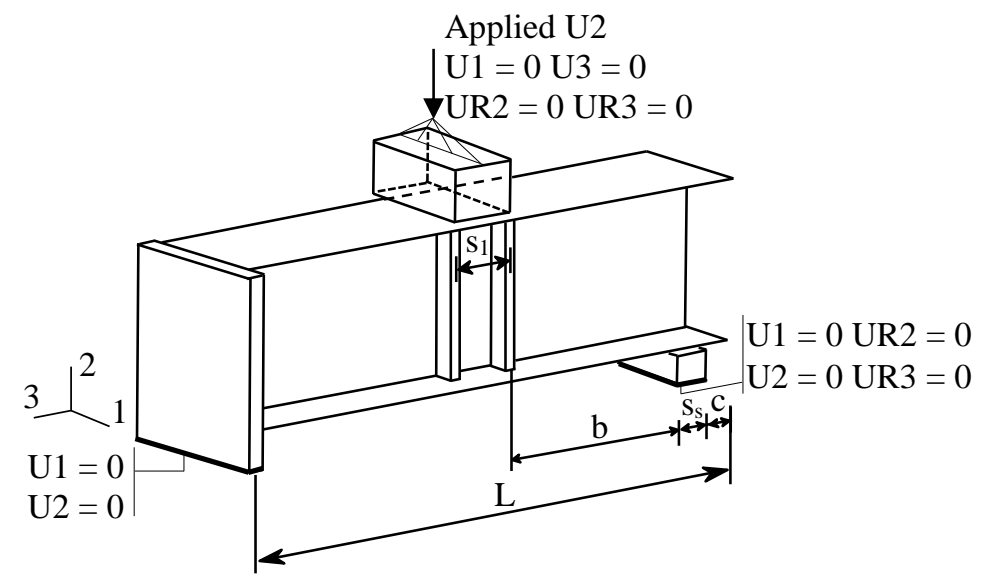

Fig. 10. Boundary conditions adopted in EOF loading finite element models. 

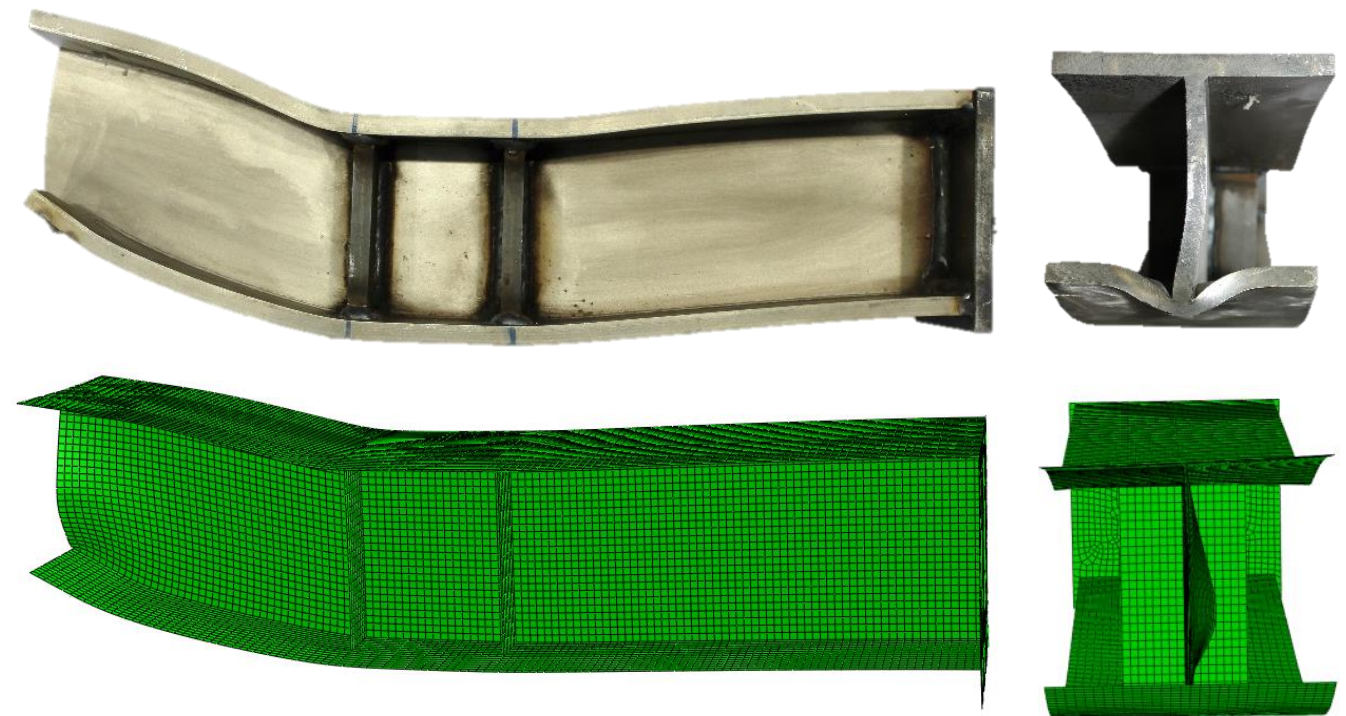

Fig. 11. Experimental and numerical failure modes of specimen EOF-h140-b180-ss30-c0.

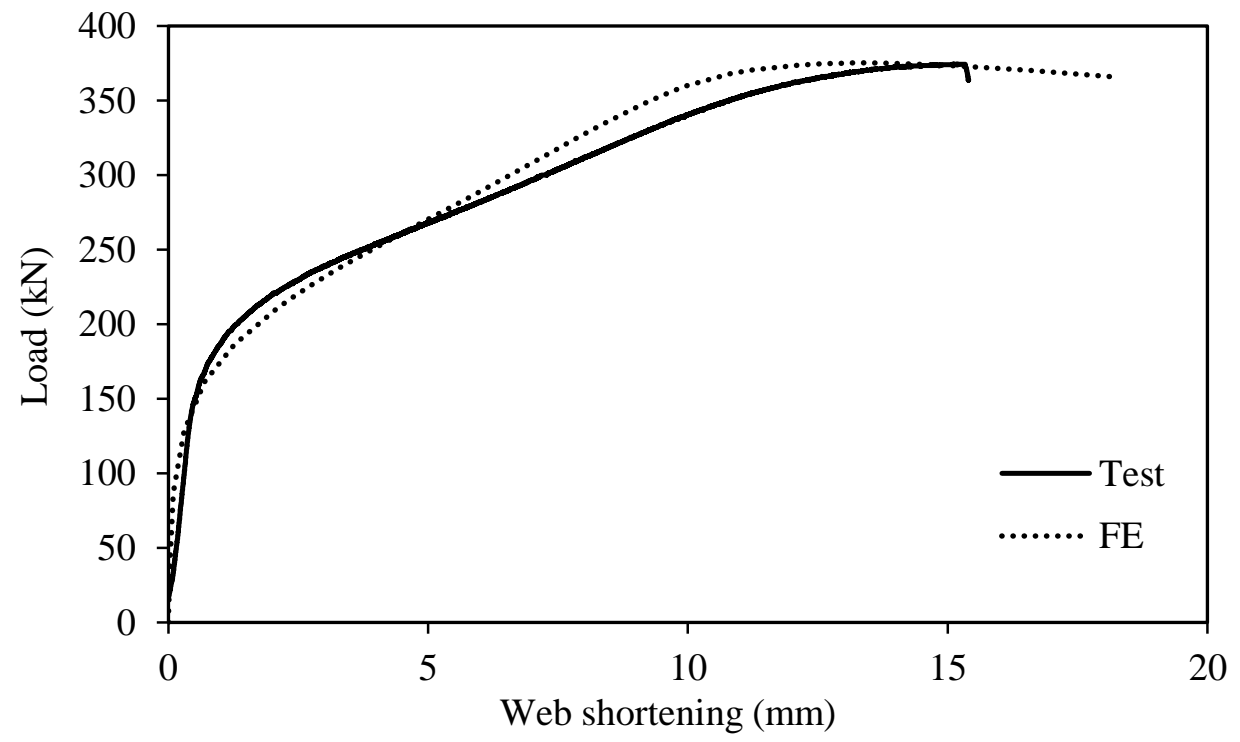

Fig. 12. Experimental and numerical load-web shortening responses of specimen EOF-h140-b180-ss30-c0. 


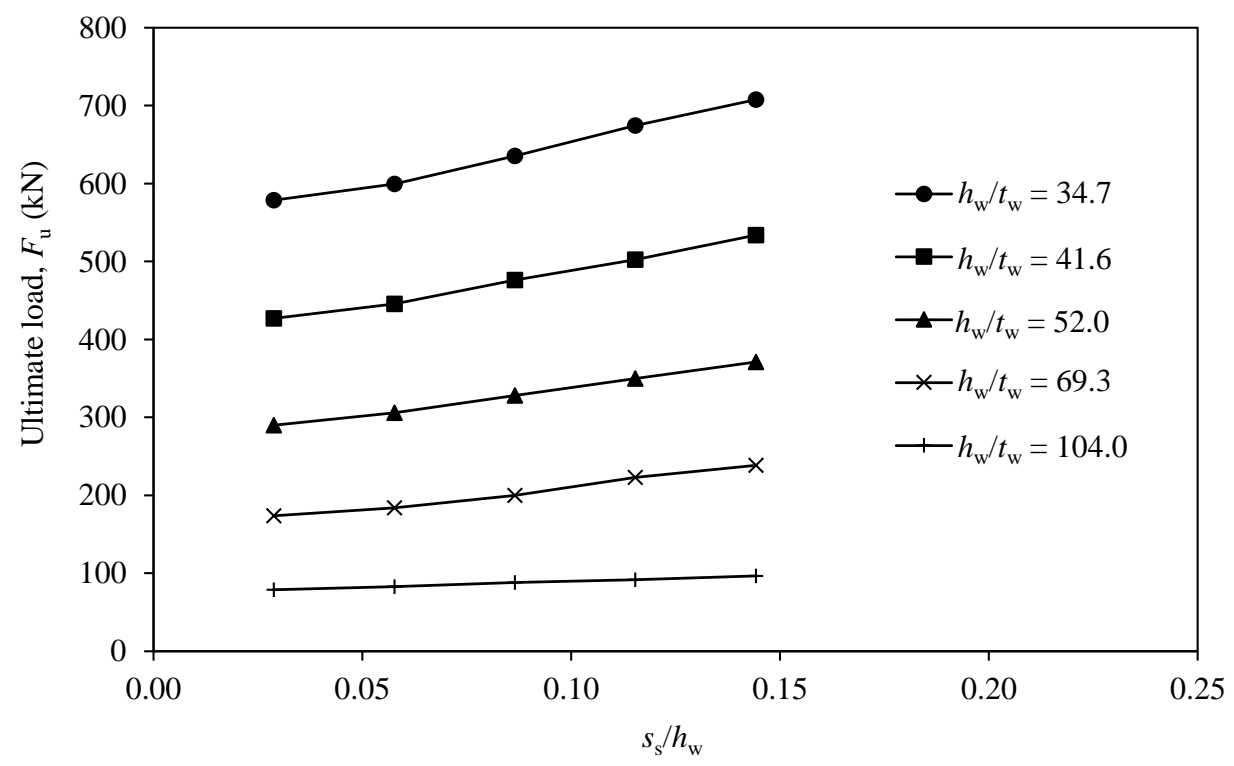

Fig. 13. Influence of normalised bearing length $s_{\mathrm{s}} / h_{\mathrm{w}}$ on the ultimate load of EOF loading models (with $c=0$ ) for different web slenderness values $h_{\mathrm{w}} / t_{\mathrm{w}}$.

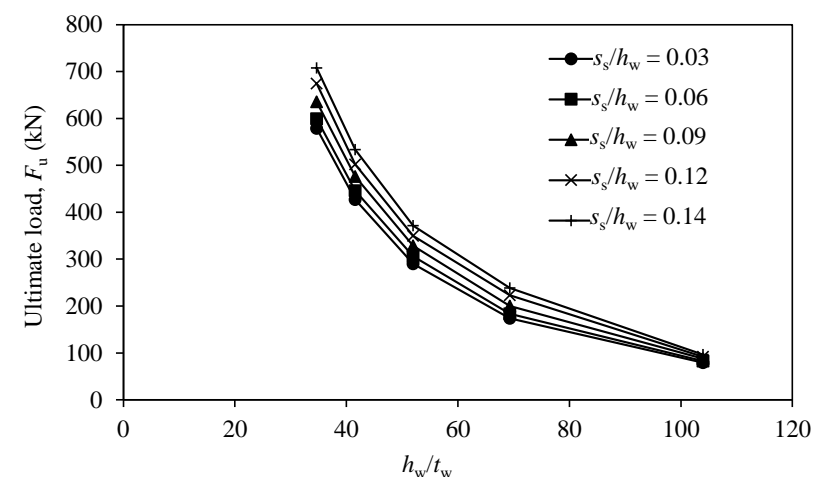

(a) Vertical axis scale up to $800 \mathrm{kN}$

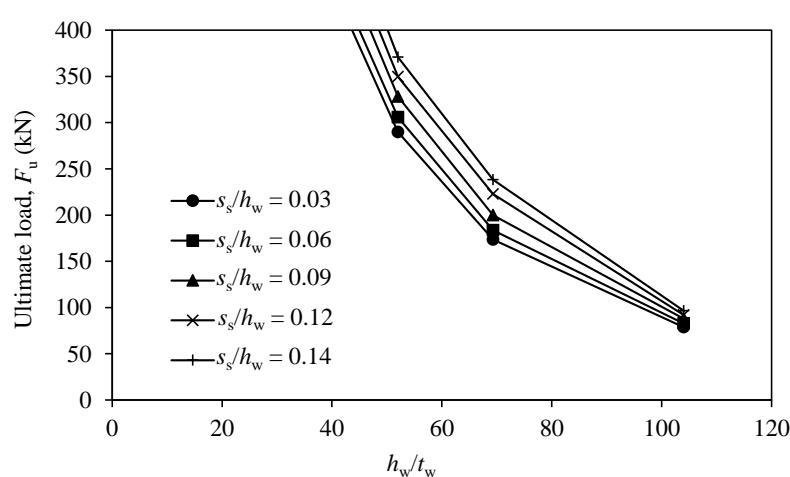

(b) Vertical axis scale up to $400 \mathrm{kN}$

Fig. 14. Influence of web slenderness $h_{\mathrm{w}} / t_{\mathrm{w}}$ on the ultimate load of EOF loading models (with $c=0$ ) for different bearing length to web height $s_{s} / h_{\mathrm{w}}$ ratios. 


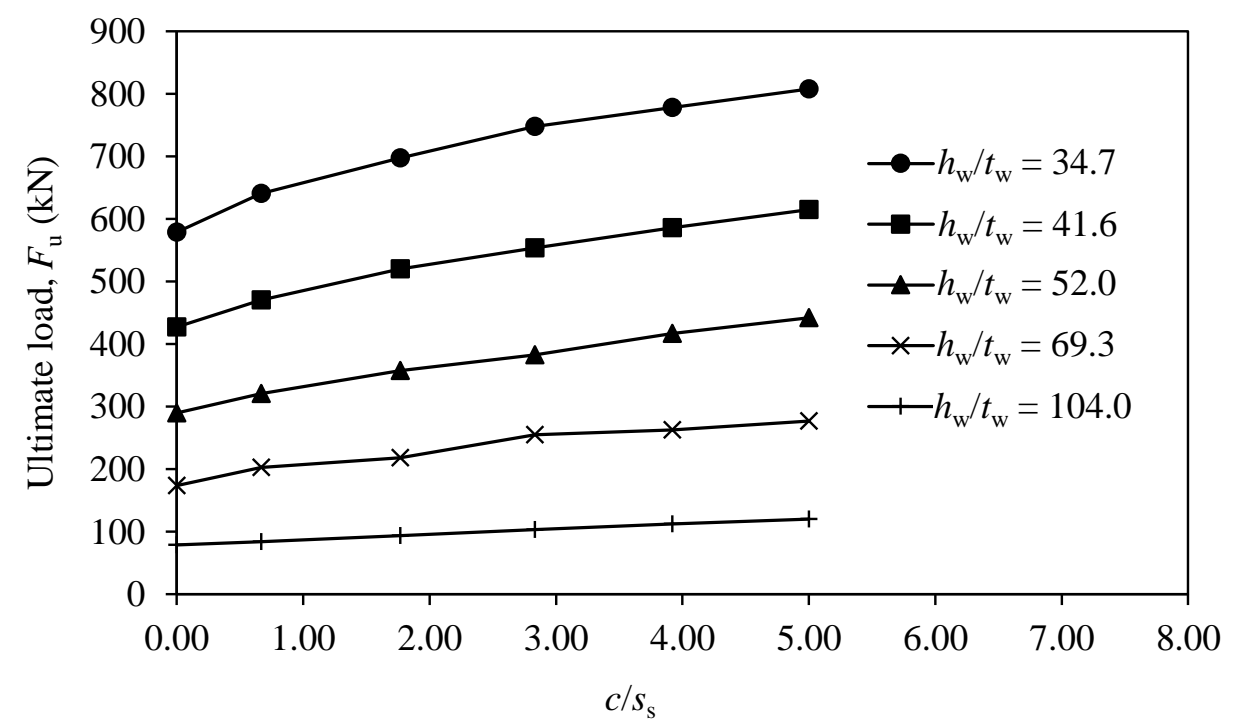

Fig. 15. Influence of $c / s_{\mathrm{s}}$ ratio on the ultimate load of EOF loading models with $s_{\mathrm{s}}=15 \mathrm{~mm}$ for different web slenderness values $h_{\mathrm{w}} / t_{\mathrm{w}}$.

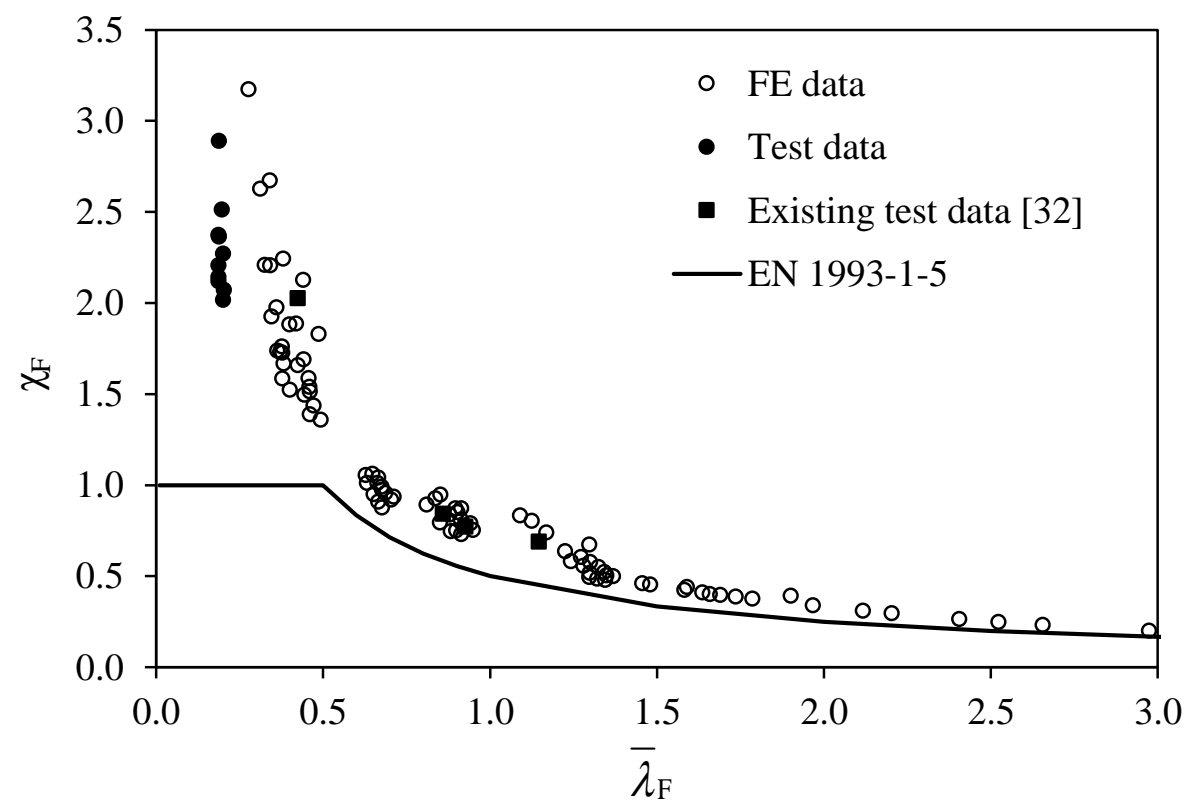

Fig. 16. Comparison of normalised ultimate loads from EOF loading tests and FE simulations with EC3 design curve. 


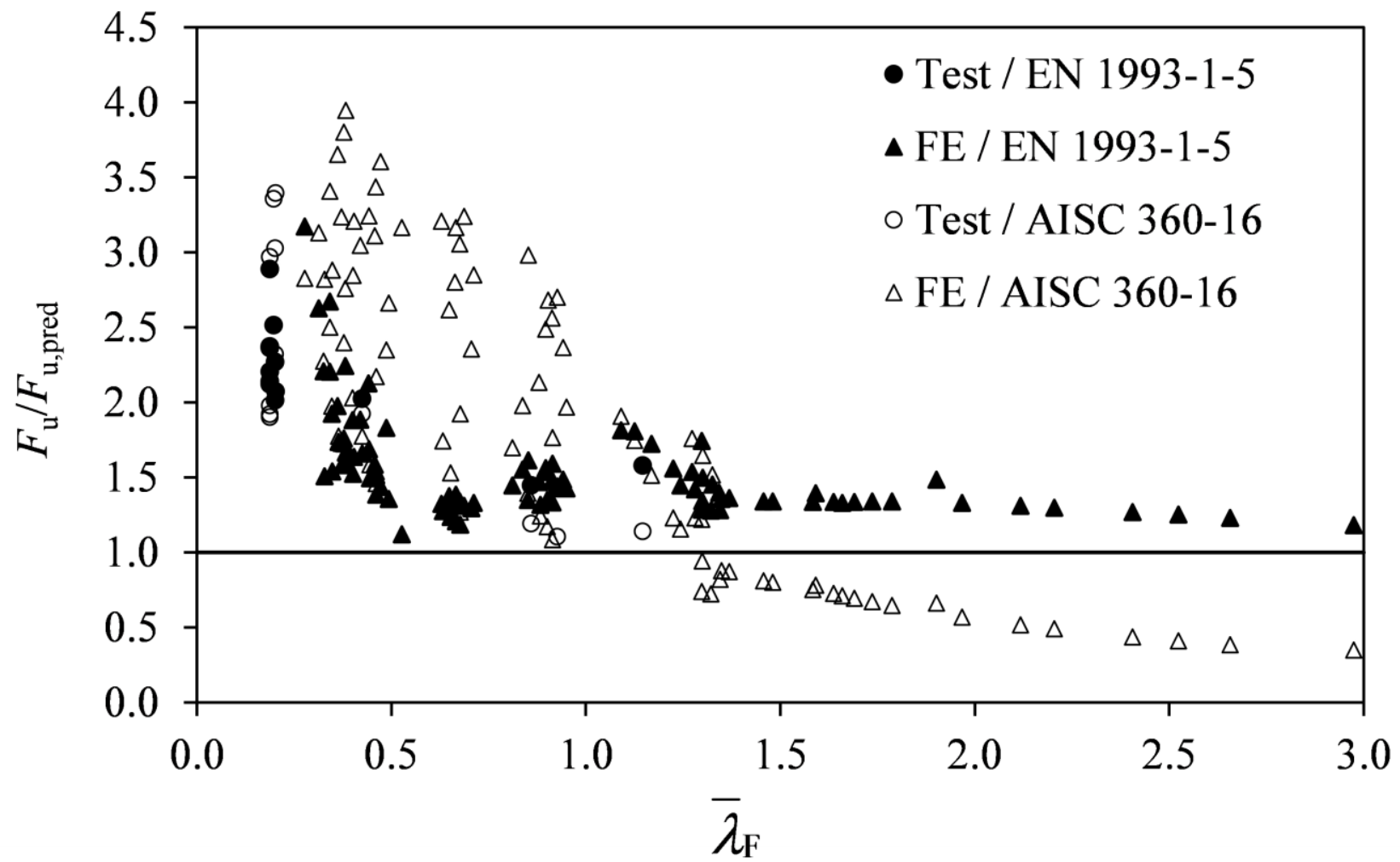

Fig. 17. Comparison of EOF loading test and FE results with European and North American design resistance predictions. 


\section{TABLES}

Table 1. Summary of material properties measured from tensile coupon tests [43].

\begin{tabular}{lcccccc}
\hline \multicolumn{1}{c}{ Specimen } & $E$ & $f_{\mathrm{y}}$ & $f_{1.0}$ & $f_{\mathrm{u}}$ & $\varepsilon_{\mathrm{u}}$ & $\varepsilon_{\mathrm{f}}$ \\
& $\left(\mathrm{N} / \mathrm{mm}^{2}\right)$ & $\left(\mathrm{N} / \mathrm{mm}^{2}\right)$ & $\left(\mathrm{N} / \mathrm{mm}^{2}\right)$ & $\left(\mathrm{N} / \mathrm{mm}^{2}\right)$ & $(\%)$ & $(\%)$ \\
\hline I $140 \times 140 \times 10 \times 12(\mathrm{Web})$ & 186800 & 260 & 312 & 617 & 55 & 66 \\
I $140 \times 140 \times 10 \times 12$ (Flange) & 193700 & 272 & 328 & 615 & 50 & 64 \\
I $160 \times 82 \times 10 \times 12$ (Web) & 198500 & 264 & 341 & 618 & 53 & 64 \\
I $160 \times 82 \times 10 \times 12$ (Flange) & 197500 & 286 & 342 & 619 & 52 & 65 \\
\hline
\end{tabular}


Accepted Manuscript.

Article accepted for publication in the journal of Constructional Steel Research, 01/06/2019.

Table 2. Summary of measured dimensions, geometric imperfections and results from the EOF loading tests.

\begin{tabular}{|c|c|c|c|c|c|c|c|c|c|c|c|c|c|c|c|c|c|c|c|}
\hline Specimen & $\begin{array}{c}h \\
(\mathrm{~mm}) \\
\end{array}$ & $\begin{array}{c}t_{\mathrm{w}} \\
(\mathrm{mm}) \\
\end{array}$ & $\begin{array}{c}b_{\mathrm{f}} \\
(\mathrm{mm}) \\
\end{array}$ & $\begin{array}{c}t_{\mathrm{f}} \\
(\mathrm{mm})\end{array}$ & $\begin{array}{c}a \\
(\mathrm{~mm}) \\
\end{array}$ & $\begin{array}{c}S_{\mathrm{S}}=S_{\mathrm{h}} \\
(\mathrm{mm})\end{array}$ & $\begin{array}{c}b \\
(\mathrm{~mm})\end{array}$ & $\begin{array}{c}c \\
(\mathrm{~mm}) \\
\end{array}$ & $\begin{array}{c}L \\
(\mathrm{~mm})\end{array}$ & $\begin{array}{c}h_{\mathrm{ep}} \\
(\mathrm{mm})\end{array}$ & $\begin{array}{c}b_{\mathrm{f}, \mathrm{ep}} \\
(\mathrm{mm})\end{array}$ & $\begin{array}{c}t_{\mathrm{ep}} \\
(\mathrm{mm}) \\
\end{array}$ & $\begin{array}{c}h_{\mathrm{s}} \\
(\mathrm{mm})\end{array}$ & $\begin{array}{c}b_{\mathrm{s}} \\
(\mathrm{mm})\end{array}$ & $\begin{array}{c}t_{\mathrm{s}} \\
(\mathrm{mm}) \\
\end{array}$ & $h_{\mathrm{w}} / t_{\mathrm{w}}$ & $\begin{array}{c}\omega_{0} \\
(\mathrm{~mm})\end{array}$ & $\begin{array}{c}F_{\mathrm{u}} \\
(\mathrm{kN})\end{array}$ & $\begin{array}{c}\delta_{\mathrm{u}} \\
(\mathrm{mm})\end{array}$ \\
\hline EOF-h140-b180-ss15-c0 & 139.1 & 9.62 & 140.5 & 11.81 & 187.8 & 15.0 & 179.2 & 0.0 & 601.2 & 150.0 & 149.9 & 11.91 & 115.5 & 37.9 & 12.67 & & 0.001 & 367.9 & 10.8 \\
\hline EOF-h140-b180-ss15-c10* & 139.2 & 9.61 & 140.3 & 11.78 & 197.6 & 15.0 & 178.9 & 10.0 & 600.7 & 150.0 & 149.9 & 11.94 & 115.6 & 38.0 & 12.72 & 12.0 & 0.004 & 414.7 & 9.4 \\
\hline EOF-h140-b180-ss15-c20* & 139.1 & 9.60 & 140.3 & 11.77 & 207.2 & 15.0 & 178.5 & 20.0 & 601.5 & 150.0 & 149.9 & 11.91 & 115.6 & 37.8 & 12.71 & 12.0 & 0.029 & 418.9 & 14.4 \\
\hline EOF-h140-b180-ss30-c0* & 139.2 & 9.62 & 140.3 & 11.78 & 203.5 & 30.0 & 179.8 & 0.0 & 601.0 & 150.0 & 150.0 & 11.93 & 115.6 & 38.0 & 12.69 & 12.0 & 0.005 & 374.3 & 15.1 \\
\hline EOF-h140-b180-ss30-c10* & 139.3 & 9.65 & 140.3 & 11.82 & 210.8 & 30.0 & 177.2 & 10.0 & 600.7 & 150.0 & 149.9 & 11.91 & & 37.8 & & 12.0 & 0.009 & & 14.0 \\
\hline EOF-h160-b170-ss15-c0 & 160.0 & 9.77 & 82.7 & 11.74 & 178.5 & 15.0 & 169.5 & 0.0 & 501.0 & 168.8 & 89.7 & 12.01 & 136.5 & 18.8 & & 14.0 & 0.125 & 271.0 & 10.4 \\
\hline EOF-h160-b180-ss15-c0 & 160.1 & 9.78 & 82.8 & & 186.3 & 15.0 & 177.3 & 0.0 & 501.5 & 169.0 & 89.8 & 12.01 & 136.6 & 19.0 & 11.97 & 14.0 & 0.271 & 242.3 & 10.4 \\
\hline EOF-h160-b190-ss15-c0 & 159.9 & 9.76 & 82.6 & 11.71 & 199.8 & 15.0 & 190.8 & 0.0 & 501.3 & 168.8 & 89.8 & 11.95 & 136.5 & 19.0 & 11.90 & 14.0 & 0.348 & 243.9 & 8.0 \\
\hline EOF-h160-b200-ss15-c0 & 160.1 & 9.76 & 82.7 & 11.75 & 205.5 & 15.0 & 196.5 & 0.0 & 500.7 & 168.8 & 89.7 & 12.01 & 136.6 & 18.8 & 11.94 & 14.0 & 0.062 & 269.6 & 9.7 \\
\hline EOF-h160-b210-ss15-c0 & 160.0 & 9.76 & 82.8 & 11.74 & 215.2 & 15.0 & 206.1 & 0.0 & 500.8 & 168.8 & 89.7 & 12.00 & 136.5 & 18.7 & 11.81 & 14.0 & 0.121 & 251.7 & 9.7 \\
\hline
\end{tabular}

* Bending plus shear was the critical design check. 
Accepted Manuscript.

Article accepted for publication in the journal of Constructional Steel Research, 01/06/2019.

Table 3. Comparison of EOF loading test results with FE results for different imperfection amplitudes.

\begin{tabular}{lccccc}
\hline \multirow{2}{*}{ Specimen } & \multicolumn{2}{c}{ Measured amplitude } & & \multicolumn{2}{c}{$t_{\mathrm{w}} / 500$} \\
\cline { 2 - 3 } \cline { 5 - 6 } & $F_{\mathrm{u}, \mathrm{FE}} / F_{\mathrm{u}, \mathrm{Test}}$ & $\delta_{\mathrm{u}, \mathrm{FE}} / \delta_{\mathrm{u}, \mathrm{Test}}$ & & $F_{\mathrm{u}, \mathrm{FE}} / F_{\mathrm{u}, \mathrm{Test}}$ & $\delta_{\mathrm{u}, \mathrm{FE}} / \delta_{\mathrm{u}, \mathrm{Test}}$ \\
\hline EOF-h140-b180-ss15-c0 & 0.95 & 1.79 & & 0.81 & 1.66 \\
EOF-h140-b180-ss15-c10 & 0.94 & 1.23 & & 0.85 & 0.91 \\
EOF-h140-b180-ss15-c20 & 1.03 & 0.75 & & 1.07 & 0.65 \\
EOF-h140-b180-ss30-c0 & 1.00 & 0.89 & & 0.92 & 0.52 \\
EOF-h140-b180-ss30-c10 & 0.95 & 0.80 & & 0.89 & 0.49 \\
EOF-h160-b170-ss15-c0 & 0.96 & 1.40 & & 1.06 & 1.29 \\
EOF-h160-b180-ss15-c0 & 1.02 & 1.22 & & 1.18 & 1.30 \\
EOF-h160-b190-ss15-c0 & 0.99 & 1.45 & & 1.17 & 1.69 \\
EOF-h160-b200-ss15-c0 & 1.00 & 1.63 & & 1.05 & 1.40 \\
EOF-h160-b210-ss15-c0 & 1.03 & 1.46 & & 1.13 & 1.39 \\
\hline Mean & 0.99 & 1.26 & & 1.01 & 1.13 \\
COV & 0.04 & 0.28 & & 0.13 & 0.40 \\
\hline
\end{tabular}


Table 4. Design resistance functions for members under concentrated end-one-flange loading from AISC 36016 [53].

\begin{tabular}{cl}
\hline Limit state & Resistance \\
\hline $\begin{array}{c}\text { Web local yielding } \\
\text { AISC 360-16 [53], J10.2 }\end{array}$ & $\begin{array}{l}\text { If } c+s_{\mathrm{s}}>h: F_{\mathrm{Rd}}=f_{\mathrm{yw}} t_{\mathrm{w}}\left(5 k+s_{\mathrm{s}}\right) \\
\text { where } k \text { is the distance from outer face of the flange to the web fillet toe. }\end{array}$ \\
\hline Web local crippling & If $c \geq h / 2: F_{\mathrm{Rd}}=0.80 t_{\mathrm{w}}^{2}\left[1+3\left(\frac{s_{\mathrm{s}}}{h}\right)\left(\frac{t_{\mathrm{w}}}{t_{\mathrm{f}}}\right)^{1.5}\right] \sqrt{\frac{E f_{\mathrm{yw}} t_{\mathrm{f}}}{t_{\mathrm{w}}}}$ \\
AISC 360-16 [53], J10.3 & If $c<h / 2:$ \\
& For $s_{\mathrm{s}} / h \leq 0.2: F_{\mathrm{Rd}}=0.40 t_{\mathrm{w}}^{2}\left[1+3\left(\frac{s_{\mathrm{s}}}{h}\right)\left(\frac{t_{\mathrm{w}}}{t_{\mathrm{f}}}\right)^{1.5}\right] \sqrt{\frac{E f_{\mathrm{yw}} t_{\mathrm{f}}}{t_{\mathrm{w}}}}$ \\
& For $s_{\mathrm{s}} / h>0.2: F_{\mathrm{Rd}}=0.40 t_{\mathrm{w}}^{2}\left[1+\left(\frac{4 s_{\mathrm{s}}}{h}-0.2\right)\left(\frac{t_{\mathrm{w}}}{t_{\mathrm{f}}}\right)^{1.5}\right] \sqrt{\frac{E f_{\mathrm{yw}} t_{\mathrm{f}}}{t_{\mathrm{w}}}}$ \\
\hline
\end{tabular}


Table 5. Comparisons of EOF loading tests and FE results with the ultimate web bearing resistances predicted by EC3 and AISC 360-16.

(a) All cases

No. of tests: $10 \quad F_{\mathrm{u}} / F_{\mathrm{u}, \mathrm{EC} 3} \quad F_{\mathrm{u}} / F_{\mathrm{u}, \mathrm{AISC}}$

No. of FE simulations: 90

Mean

$1.59 \quad 1.86$

$\mathrm{COV}$

$0.24 \quad 0.50$

(b) $h_{\mathrm{w}} / t_{\mathrm{w}}<20$

No. of tests: $6 \quad F_{\mathrm{u}} / F_{\mathrm{u}, \mathrm{EC} 3} \quad F_{\mathrm{u}} / F_{\mathrm{u}, \mathrm{AISC}}$

No. of FE simulations: 0

Mean

$2.35 \quad 2.17$

$\mathrm{COV}$

$0.12 \quad 0.19$

(c) $20 \leq h_{\mathrm{w}} / t_{\mathrm{w}}<40$

No. of tests: $0 \quad F_{\mathrm{u}} / F_{\mathrm{u}, \mathrm{EC} 3} \quad F_{\mathrm{u}} / F_{\mathrm{u}, \mathrm{AISC}}$

No. of FE simulations: 13

Mean

$1.99 \quad 2.84$

$\mathrm{COV}$

$0.24 \quad 0.27$

(d) $40 \leq h_{\mathrm{w}} / t_{\mathrm{w}}<50$

No. of tests: $1 \quad F_{\mathrm{u}} / F_{\mathrm{u}, \mathrm{EC} 3} \quad F_{\mathrm{u}} / F_{\mathrm{u}, \mathrm{AISC}}$

No. of FE simulations: 13

Mean

$\begin{array}{ll}1.74 & 2.52\end{array}$

COV

$0.21 \quad 0.28$

(e) $50 \leq h_{\mathrm{w}} / t_{\mathrm{w}}<60$

No. of tests: $2 \quad F_{\mathrm{u}} / F_{\mathrm{u}, \mathrm{EC} 3} \quad F_{\mathrm{u}} / F_{\mathrm{u}, \mathrm{AISC}}$

No. of FE simulations: 15

\begin{tabular}{lll} 
Mean & 1.40 & 2.23 \\
COV & 0.17 & 0.34 \\
\hline
\end{tabular}

(f) $60 \leq h_{\mathrm{w}} / t_{\mathrm{w}}<80$

No. of tests: $1 \quad F_{\mathrm{u}} / F_{\mathrm{u}, \mathrm{EC} 3} \quad F_{\mathrm{u}} / F_{\mathrm{u}, \mathrm{AISC}}$

No. of FE simulations: 15

Mean

$1.47 \quad 1.96$

COV

$0.07 \quad 0.32$

(g) $80 \leq h_{\mathrm{w}} / t_{\mathrm{w}}<110$

No. of tests: $0 \quad F_{\mathrm{u}} / F_{\mathrm{u}, \mathrm{EC} 3} \quad F_{\mathrm{u}} / F_{\mathrm{u}, \mathrm{AISC}}$

No. of FE simulations: 16

Mean

$1.50 \quad 1.28$

COV

0.12

0.30

(h) $110 \leq h_{\mathrm{w}} / t_{\mathrm{w}}<245$

No. of tests: $0 \quad F_{\mathrm{u}} / F_{\mathrm{u}, \mathrm{EC} 3} \quad F_{\mathrm{u}} / F_{\mathrm{u}, \mathrm{AISC}}$

No. of FE simulations: 18

Mean

$1.32 \quad 0.63$

$\mathrm{COV}$

$0.05 \quad 0.26$

